\title{
Chemical characterization of biogenic secondary organic aerosol generated from plant emissions under baseline and stressed conditions: inter- and intra-species variability for six coniferous species
}

\author{
C. L. Faiola ${ }^{1, *}$, M. Wen ${ }^{1}$, and T. M. VanReken ${ }^{1}$ \\ ${ }^{1}$ Laboratory for Atmospheric Research, Department of Civil and Environmental Engineering, \\ Washington State University, Pullman, Washington, USA \\ * now at: Department of Applied Physics, University of Eastern Finland, Kuopio, Finland
}

Correspondence to: T. M. VanReken (vanreken@wsu.edu)

Received: 6 September 2014 - Published in Atmos. Chem. Phys. Discuss.: 1 October 2014

Revised: 19 January 2015 - Accepted: 12 March 2015 - Published: 1 April 2015

\begin{abstract}
The largest global source of secondary organic aerosol (SOA) in the atmosphere is derived from the oxidation of biogenic emissions. Plant stressors associated with a changing environment can alter both the quantity and composition of the compounds that are emitted. Alterations to the biogenic volatile organic compound (BVOC) profile could impact the characteristics of the SOA formed from those emissions. This study investigated the impacts of one global change stressor, increased herbivory, on the composition of SOA derived from real plant emissions. Herbivory was simulated via application of methyl jasmonate (MeJA), a proxy compound. Experiments were repeated under pre- and posttreatment conditions for six different coniferous plant types. Volatile organic compounds (VOCs) emitted from the plants were oxidized to form SOA via dark ozone-initiated chemistry. The SOA chemical composition was measured using a Aerodyne high-resolution time-of-flight aerosol mass spectrometer (HR-AMS). The aerosol mass spectra of pretreatment biogenic SOA from all plant types tended to be similar with correlations usually greater than or equal to 0.90 . The presence of a stressor produced characteristic differences in the SOA mass spectra. Specifically, the following $m / z$ were identified as a possible biogenic stress AMS marker with the corresponding $\mathrm{HR}$ ion(s) shown in parentheses: $m / z 31\left(\mathrm{CH}_{3} \mathrm{O}^{+}\right), m / z 58\left(\mathrm{C}_{2} \mathrm{H}_{2} \mathrm{O}_{2}^{+}, \mathrm{C}_{3} \mathrm{H}_{6} \mathrm{O}^{+}\right), m / z 29$ $\left(\mathrm{C}_{2} \mathrm{H}_{5}^{+}\right), m / z 57\left(\mathrm{C}_{3} \mathrm{H}_{5} \mathrm{O}^{+}\right), m / z 59\left(\mathrm{C}_{2} \mathrm{H}_{3} \mathrm{O}_{2}^{+}, \mathrm{C}_{3} \mathrm{H}_{7} \mathrm{O}^{+}\right)$, $m / z 71\left(\mathrm{C}_{3} \mathrm{H}_{3} \mathrm{O}_{2}^{+}, \mathrm{C}_{4} \mathrm{H}_{7} \mathrm{O}^{+}\right)$, and $m / z 83\left(\mathrm{C}_{5} \mathrm{H}_{7} \mathrm{O}^{+}\right)$. The
\end{abstract}

first aerosol mass spectrum of SOA generated from the oxidation of the plant stress hormone, MeJA, is also presented. Elemental analysis results demonstrated an $\mathrm{O}: \mathrm{C}$ range of baseline biogenic SOA between 0.3 and 0.47 . The $\mathrm{O}: \mathrm{C}$ of standard MeJA SOA was 0.52. Results presented here could be used to help identify a biogenic plant stress marker in ambient data sets collected in forest environments.

\section{Introduction}

Organic material comprises $20-90 \%$ of the mass in atmospheric particles smaller than 1 micrometer (Jimenez et al., 2009; Zhang et al., 2007). Most of this small organic particulate material is secondary organic aerosol (SOA), and the major fraction of SOA globally is formed from the oxidation of biogenic volatile organic compounds (BVOCs) released by vegetation (Hallquist et al., 2009). BVOCs are emitted by plants primarily for defensive purposes (Dudareva et al., 2006; Kesselmeier and Staudt, 1999). BVOC emission rates and emission profiles (i.e., the types of compounds emitted) can change significantly when plants are exposed to biotic and abiotic stressors (Holopainen, 2004; Peñuelas and Staudt, 2010; Pinto et al., 2010). It follows then that plant stress exposure associated with climate change could have significant impacts on SOA formation, and thus could lead to a climate feedback because atmospheric aerosols play an important role in the global radiation budget. 
Potential climate change feedbacks resulting from the processes linking naturally produced aerosols and the rest of the Earth system have been summarized by Carslaw et al. (2010). These processes include the production of secondary sulfate aerosol from phytoplankton emissions, physical processes that contribute to dust entrainment, and the formation of biogenic SOA from terrestrial plant emissions. Their simulations estimated that the radiative forcing resulting from these feedbacks could produce positive radiative perturbations up to $1 \mathrm{~W} \mathrm{~m}^{-2}$ by the end of the 21 st century, amplifying the expected effects of climate change (Carslaw et al., 2010). Another review focused on feedbacks between the terrestrial biosphere and climate, and also included a discussion of the biogenic SOA formation process (Arneth et al., 2010). They estimated that climate feedbacks with the terrestrial biosphere could result in positive radiative perturbations of up to $1.5 \mathrm{~W} \mathrm{~m}^{-2} \mathrm{~K}^{-1}$ by the end of the 21 st century. Both reviews make clear that more work is required to fully understand these feedbacks, stating that the current level of scientific understanding for them is poor (Carslaw et al., 2010) and very low (Arneth et al., 2010). Despite the uncertainty in these projections, the assessments of both papers are in stark contrast to the previously held assumption that the overall contribution of vegetation to the changing climate system is to act as a sink for increasing $\mathrm{CO}_{2}$ (Magnani et al., 2007). Carslaw et al. (2010) listed several research topics that need to be addressed in order to reduce the uncertainty in these predictions; resolving BVOC responses to climate change stressors and investigating the subsequent impact on biogenic SOA formation was included as a high priority for future research projects.

Most studies of how BVOC emissions respond to stressors have focused solely on the BVOC emissions themselves. Using these results to infer overall impacts on climate requires highly uncertain assumptions about how different mixtures of BVOCs could impact SOA yields and chemical composition. A few studies have examined SOA formation from real plant emissions more directly. Joutsensaari et al. (2005) were the first to report SOA formation in a laboratory chamber from the oxidation of real plant emissions. They used a methyl jasmonate (MeJA) treatment to induce emissions in order to investigate the role of inducible plant volatiles in particle nucleation and growth. Other studies have focused on SOA production and chemical composition from BVOC emissions under baseline conditions, rather than looking at potential feedbacks between stressors and climate (Hao et al., 2011; Kiendler-Scharr et al., 2009; Mentel et al., 2009; VanReken et al., 2006). Our own recent work showed that SOA can also form from BVOCs emitted from leaf litter, and that this aerosol is chemically very similar to SOA produced from live tree emissions (Faiola et al., 2014). BVOC emissions from leaf litter were also found to respond to external environmental drivers, raising the possibility of additional pathways for climate feedbacks to occur.
Recently, there have been two studies that compared biogenic SOA yields for baseline emission versus stressed conditions. Lang-Yona et al. (2010) examined the effect of increased temperature on holm oak (Quercus ilex) emissions and subsequent SOA formation, finding that increased temperature led to heightened BVOC emissions and increased SOA production. The BVOC profile was slightly altered with increasing temperature, but this did not impact the resultant SOA mass yields. In another study, Mentel et al. (2013) investigated the impact of herbivory, drought, and heat stress on biogenic SOA yields. They found that the measured impact on SOA formation was different for different stressors. For example, infestation by the aphid Cinara pilicornis resulted in emissions of large organic compounds that had higher SOA yields than the baseline emissions (33\% stress yield vs. 4-6\% baseline yield). However, if the plants were experiencing both herbivory and drought stress concurrently, emissions of small six-carbon green leaf volatiles increased, which reduced biogenic SOA yields. These results suggest that climate change could have significant impacts on biogenic SOA formation, and furthermore, that multiple stressors can interact to change the SOA formation potential of BVOC emissions in a different way than a single stressor in isolation. These previous plant stress SOA formation studies provide valuable insight into the potential impacts of climate change stressors on biogenic SOA yields. However, to date there have been no in-depth analyses to investigate how plant stress may affect biogenic SOA composition, which would have implications for aerosol radiative properties and cloud forming potential. The research described in this paper addresses these gaps in our current understanding of the variability in biogenic SOA composition - including a discussion of inter- and intra-plant species variability as well as a first look at some impacts of herbivore stress on biogenic SOA composition.

\section{Methods}

\subsection{Description of dual chamber system and operation}

The experiments presented here were performed using the Biogenic Aerosol Formation Facility at Washington State University. This dual chamber facility uses emissions from living vegetation as the precursor volatile organic compound (VOC) source for SOA formation. This is in contrast to other systems that have historically used commercially obtained pure compounds as a proxy for biogenic emissions. The facility includes a dynamic plant enclosure and an aerosol growth chamber. The plant enclosure is a rectangular $0.3 \times 0.3 \times 0.3 \mathrm{~m}$ fluorinated ethylene propylene $(\mathrm{FEP})$ Teflon film dynamic enclosure where sapling trees are stored. A full description of the plant enclosure and the on-line analytical gas chromatography (GC) system used to measure BVOC emissions is provided in a separate paper that focuses 
on the impacts of herbivory stress on plant emissions (Faiola et al., 2015). The current paper focuses specifically on the composition of biogenic SOA formed from the oxidation of the plant emissions.

The aerosol growth chamber operation and SOA generation methods are similar to those described by Faiola et al. (2014). Chamber dimensions were $1.6 \times 2.2 \times 2.2 \mathrm{~m}$. All aerosol growth experiments were conducted with the chamber using a batch mode approach. Oxidation of SOA precursors was initiated with ozone that was generated with an Enaly model HG-1500 ozone generator. The chemistry in this chamber is best described as dark ozone-initiated chemistry because the chamber was not equipped with UV lights and no $\mathrm{OH}$ scavenger was used. Most experiments were unseeded. Experiments where $50 \mathrm{~nm}$ ammonium sulfate seed particles were used are marked with an asterisk in the experiment summary table (Table 1). When used, seed particles were produced from a TSI constant output atomizer (model 3076) and then size selected with a differential mobility analyzer (DMA, TSI, Inc.). Temperature and relative humidity in the aerosol growth chamber were not controlled, but were monitored using a Vaisala HMP110 humidity and temperature probe. Nitrogen oxides were not measured, but the aerosol chamber likely contained some $\mathrm{NO}_{\mathrm{x}}$ due to soil emissions from the plant pots (Davidson and Kingerlee, 1997).

\subsection{Tree description and experimental design}

Six different coniferous plant species were used as emissions sources to generate biogenic SOA in this study: ponderosa pine (Pinus ponderosa), bristlecone pine (Pinus aristata), blue spruce (Picea pungens), western redcedar (Thuja plicata), grand fir (Abies grandis), and Douglas fir (Pseudotsuga menziesii). All tree species are commonly found in the western mountain ranges of North America. Saplings were 1-3 years old at the time of the experiments. All specimens were obtained from the University of Idaho forest nursery, and were stored outdoors at the Washington State University greenhouse facility when they were not being used for experiments. Greenhouse staff cared for the specimens, providing regular watering and fertilization.

Plants were transported to the laboratory at least $36 \mathrm{~h}$ before the first aerosol growth chamber experiment to allow time for acclimation to laboratory conditions. Three to nine saplings of the same species were placed in the plant enclosure (the number depended on the size of the plants). The only exceptions to this were four experiments performed using a combination of Abies grandis and Pseudotsuga menziesii specimens rather than just a single plant species (referred to as mix experiments). One day before an aerosol growth experiment, the aerosol growth chamber was cleaned with $1 \mathrm{ppm}$ ozone and flushed with zero air for at least $18 \mathrm{~h}$ until ozone concentrations were less than $20 \mathrm{ppb}$ (Model 1008-PC ozone monitor, Dasibi) and particle number concentrations were less than $10 \mathrm{~cm}^{-3}$ (Model 3771 conden- sation particle counter, TSI, Inc.). Zero air was generated with a pure air generator (AADCO model 737). Chamber flushing was stopped on the morning of the experiment, at which point the chamber was operated in batch mode. Biogenic VOC emissions were pumped from the plant enclosure to the aerosol growth chamber for $3 \mathrm{~h}\left(\right.$ flow $\left.=9.5 \mathrm{~L} \mathrm{~min}^{-1}\right)$ using a chemically resistant vacuum pump (KNF Laboport model UN810 FTP) through Perfluoroalkoxy alkanes (PFA) lines heated to $80^{\circ} \mathrm{C}$. Lines were heated to minimize losses of lower-volatility compounds. During chamber loading, a fan inside the chamber was used to facilitate mixing.

When VOC loading was complete, the oxidation chemistry was initiated by rapidly introducing $130 \mathrm{ppb}$ ozone to the aerosol growth chamber. The mixing fan was turned off immediately following oxidant addition to reduce particle wall loss. Particle growth and composition were then monitored for the next 6-8h. This process was repeated with the same batch of trees twice in 1 week - once before treatment was applied and again after the treatment. The treatment was either a stress application or a negative control. Both treatments are described in detail in the next section. The time required to observe maximum plant response to treatment can vary (Copolovici et al., 2011). Consequently, some of the post-treatment aerosol growth experiments were performed the day after treatment, and some were performed on the same day as the treatment.

A list of all experiments with the experiment ID, date, and treatment approach is provided in Table 1. The naming convention for the experiment ID is plant species type + experiment number + experiment type. For example, PA-1-Pre stands for Pinus aristata, first experiment, pretreatment, and PA-1-Post stands for Pinus aristata, first experiment, post-treatment. One pre-treatment aerosol growth experiment performed with Picea pungens specimens on 14 May 2013 did not produce enough particle mass for aerosol mass spectrometer (AMS) analysis; therefore, it has been removed from this table and will not be considered further. There was also one SOA growth experiment performed that used a single-component standard, MeJA, as the precursor compound to generate SOA, rather than using real plant emissions. For this experiment, a $95 \%$ MeJA standard solution (Sigma-Aldrich part no. 392707-5ML) was introduced into the aerosol growth chamber using a dynamic dilution system (Faiola et al., 2012).

\subsection{Stress treatment}

Herbivory stress was simulated by exposing plants to MeJA. This compound is a plant stress hormone with the chemical formula $\mathrm{C}_{13} \mathrm{H}_{20} \mathrm{O}_{3}$ that is used in plant-plant communication for defensive purposes (Cheong and Choi, 2003). Plants emit MeJA into the gas phase, where it induces the jasmonic acid defense pathway in neighboring plants (Farmer and Ryan, 1990) - a biochemical pathway that leads to changes in the VOCs produced and emitted from those 
Table 1. Experiment summary. Asterisks on experiment ID indicate that seed was used; MeJA is methyl jasmonate. The last column provides the IDs of the corresponding BVOC experiments, where available, to facilitate cross-referencing with the companion paper (Faiola et al., 2015). n/a means "not applicable".

\begin{tabular}{|c|c|c|c|c|c|c|}
\hline $\begin{array}{l}\text { SOA } \\
\text { experiment ID }\end{array}$ & Tree type (Species) & Common name & $\begin{array}{l}\text { Experiment } \\
\text { type }\end{array}$ & Date & $\begin{array}{l}\text { Treatment } \\
\text { approach }\end{array}$ & $\begin{array}{l}\text { BVOC } \\
\text { experiment } \\
\text { ID }\end{array}$ \\
\hline PPo-1-Pre* & \multirow{4}{*}{ Pinus ponderosa } & \multirow{4}{*}{ Ponderosa Pine } & Baseline & 31 July 2012 & - & - \\
\hline PPo-1-Post* & & & MeJA & 2 August 2012 & $\begin{array}{l}\text { exogenous, } \\
\text { day before }\end{array}$ & - \\
\hline \multirow{2}{*}{$\begin{array}{l}\text { PPo-2-Pre } \\
\text { PPo-2-Post }\end{array}$} & & & Baseline & 23 October 2012 & - & - \\
\hline & & & MeJA & 25 October 2012 & $\begin{array}{l}\text { exogenous, } \\
\text { day before }\end{array}$ & - \\
\hline PA-1-Pre* & \multirow{6}{*}{ Pinus aristata } & \multirow{6}{*}{ Bristlecone Pine } & Baseline & 9 October 2012 & - & - \\
\hline PA-1-Post & & & MeJA & 18 October 2012 & $\begin{array}{l}\text { exogenous, } \\
\text { day before }\end{array}$ & - \\
\hline PA-2-Pre & & & Baseline & 23 April 2013 & - & - \\
\hline PA-3-Pre & & & Baseline & 21 May 2013 & - & PA-E \\
\hline PA-3-Post & & & MeJA & 23 May 2013 & foliar, day before & PA-E \\
\hline PA-4-Pre & & & Baseline & 28 May 2013 & - & PA-C \\
\hline AG-1-Pre & \multirow{6}{*}{ Abies grandis } & \multirow{6}{*}{ Grand Fir } & Baseline & 25 June 2013 & - & AG-E \\
\hline AG-1-Post & & & MeJA & 27 June 2013 & foliar, day before & AG-E \\
\hline AG-2-Pre & & & Baseline & 3 September 2013 & - & - \\
\hline AG-2-Post & & & MeJA & 5 September 2013 & foliar, same day & - \\
\hline AG-3-Pre & & & Baseline & 10 September 2013 & - & - \\
\hline AG-3-NC & & & Negative & 12 September 2013 & foliar, same day & - \\
\hline TP-1-Pre & \multirow{7}{*}{ Thuja plicata } & \multirow{7}{*}{ Western redcedar } & Baseline & 14 August 2013 & - & - \\
\hline TP-1-Post & & & MeJA & 16 August 2013 & foliar, same day & - \\
\hline TP-2-Pre & & & Baseline & 21 August 2013 & - & - \\
\hline TP-2-NC & & & Negative & 23 August 2013 & foliar, same day & - \\
\hline TP-3-Pre1 & & & Baseline & 17 September 2013 & - & TP-E \\
\hline TP-3-Pre2 & & & Baseline & 19 September 2013 & - & TP-E \\
\hline TP-3-Post & & & MeJA & 22 September 2013 & foliar, same day & TP-E \\
\hline PPu-1-Post & \multirow{3}{*}{ Picea pungens } & \multirow{3}{*}{ Blue Spruce } & MeJA & 16 May 2013 & foliar, day before & PP-E1 \\
\hline PPu-2-Pre & & & Baseline & 16 July 2013 & - & PP-E2 \\
\hline PPu-2-Post & & & MeJA & 18 July 2013 & foliar, day before & PP-E2 \\
\hline PM-1-Pre & \multirow{4}{*}{ Pseudotsuga menziesii } & \multirow{4}{*}{ Douglas fir } & Baseline & 27 August 2013 & - & - \\
\hline PM-1-Post & & & MeJA & 29 August 2013 & foliar, same day & - \\
\hline PM-2-Pre & & & Baseline & 24 September 2013 & - & PM-E \\
\hline PM-2-Post & & & MeJA & 26 September 2013 & foliar, same day & PM-E \\
\hline \multirow{4}{*}{$\begin{array}{l}\text { Mix-1-Pre } \\
\text { Mix-1-Post } \\
\text { Mix-2-Pre } \\
\text { Mix-2-NC }\end{array}$} & \multirow{2}{*}{ Mix-Abies grandis and } & \multirow{2}{*}{ Grand Fir and } & Baseline & 24 July 2013 & - & - \\
\hline & & & MeJA & 26 July 2013 & foliar, same day & - \\
\hline & \multirow{2}{*}{ Pseudotsuga menziesii } & \multirow{2}{*}{ Douglas fir } & Baseline & 30 July 2013 & - & - \\
\hline & & & Negative & 1 August 2013 & foliar, same day & - \\
\hline MeJA SD & $\mathrm{n} / \mathrm{a}$ & $\mathrm{n} / \mathrm{a}$ & Standard & 8 May 2014 & $\mathrm{n} / \mathrm{a}$ & - \\
\hline
\end{tabular}

plants. Consequently, exposing plants to MeJA alters BVOC emission rates, their chemical profile, and their concentrations in storage pools (Martin et al., 2003; Rodriguez-Saona et al., 2001). For the 2012 experiments, MeJA was introduced using an exogenous treatment where $20 \mu \mathrm{L}$ of a $9: 1$ diluted ethanol:MeJA solution was applied to a cotton swab and placed in the biogenic emissions enclosure with the plants, following the methods of Rodriguez-Saona et al. (2001).
The 2013 experiments used a foliar application of $10 \mathrm{mM}$ MeJA in nanopure water, following the approach of Martin et al. (2003). The plant foliage was sprayed with $200 \mathrm{~mL}$ of this solution. The negative control treatment was a foliar application of $200 \mathrm{~mL}$ of nanopure water rather than the MeJA solution.

The revised MeJA treatment employed in 2013 was intended to promote a maximal herbivory stress response. The 
goal was to allow us to investigate an upper limit of the potential impacts of herbivory on biogenic SOA composition, something that has not been reported previously. The foliar MeJA stress treatment elevates BVOC emissions and typically leads to much larger mass loadings relative to the pretreatment experiments. Importantly, the purpose of these experiments was not to quantify changes to the amount of SOA formed under stressed conditions. Rather, this research seeks to fill in current gaps in knowledge by investigating changes to biogenic SOA composition due to stress.

A number of the post-treatment aerosol growth experiments were performed the same day as the foliar MeJA application. In these cases, MeJA solution remained present on the plants in the plant chamber while the aerosol chamber was being loaded. The vapor pressure of MeJA at $23{ }^{\circ} \mathrm{C}$ is $1.28 \times 10^{-4} \mathrm{mmHg}$ (Acevedo et al., 2003), which corresponds to an effective saturation concentration $\left(C^{*}\right)$ of $1500 \mu \mathrm{g} \mathrm{m}^{-3}$. This puts MeJA at the lower end of the intermediate volatility range $\left(C^{*}\right.$ range of $1000-100000 \mu \mathrm{g} \mathrm{m}^{-3}$ ) approaching the semi-volatile range $\left(C^{*}\right.$ range of $0.1-$ $1000 \mu \mathrm{g} \mathrm{m}^{-3}$ ) (Robinson et al., 2007). To compare, the vapor pressure of alpha-pinene, a typical monoterpene, is 4 orders of magnitude greater, nearly $3 \mathrm{mmHg}$ at $20^{\circ} \mathrm{C}$. Even with MeJA's low vapor pressure, some of the compound sprayed on the trees would volatilize and be subsequently pumped into the aerosol growth chamber. This MeJA could act as an SOA precursor in addition to the VOC emissions from the plant. Consequently, there are two types of post-treatment SOA in these experiments: pure plant emission post-treatment SOA and plant emission + MeJA posttreatment SOA. This latter SOA could still be considered a type of stress SOA because plants do emit significant quantities of plant hormones in forests when exposed to stressed conditions (Karl et al., 2008). The role of plant hormones in SOA formation has typically been ignored in plant SOA experiments. Recently, Richards-Henderson et al. (2014) demonstrated that aqueous phase oxidation of MeJA had an SOA mass yield of $68 \%$, suggesting that this is a compound that warrants further investigation.

\subsection{Analytical instrumentation}

SOA particle number size distributions were measured with a scanning mobility particle sizer (SMPS, custom built with major components from TSI, Inc.) described previously by Faiola et al. (2014) and Mwaniki et al. (2014). Aerosol mass spectra were continuously measured using a high-resolution time-of-flight aerosol mass spectrometer (HR-AMS, Aerodyne Research, Inc.) described in detail elsewhere (Canagaratna et al., 2007; DeCarlo et al., 2006). Briefly, the HRAMS collimates sub-micron particles into a narrow beam with an aerodynamic lens. The particle beam is directed onto a vaporizer plate held at $600^{\circ} \mathrm{C}$ that volatilizes all nonrefractory components. The volatilized fragments are then ionized with a tungsten filament with $70 \mathrm{eV}$ electron impact ionization. These mass fragments are introduced to a Tofwerk high-resolution time-of-flight mass spectrometer where they are separated by size and quantified. The HR-AMS was operated with 1 to $4.5 \mathrm{~min}$ sample averaging, alternating between general mass spectrometer (MS) mode and particle time-of-flight (p-ToF) mode. Only v-mode data were used in this study because pre-treatment experiments often did not have sufficient signal for w-mode data to be used. Ionization efficiency calibrations were performed using the brute force single particle technique with monodisperse ammonium nitrate particles generated with a constant output atomizer (TSI Model 3076).

\subsection{AMS data analysis}

The goal of this research was to compare the aerosol mass spectra between SOA formed from the oxidation of emissions from different types of trees and between SOA formed under pre-treatment vs. post-treatment conditions. In the past, unit-mass resolution (UMR) data from the Aerodyne HR-AMS has been normalized to the sum of the organic mass to compare spectra between different experiments with different mass loadings (Sage et al., 2008). One way these UMR spectra can be quantitatively compared is to calculate the square of the Pearson correlation coefficient $\left(r^{2}\right)$, called the coefficient of determination, between the two spectra (Kiendler-Scharr et al., 2009). Using this approach, Kiendler-Scharr and colleagues observed clear differences between biogenic SOA and other types of organic aerosol including biomass burning organic aerosol $\left(r^{2}=0.44-0.51\right)$, diesel exhaust organic aerosol $\left(r^{2}=0.44-0.51\right)$, and ambient hydrocarbon-like organic aerosol in Pittsburgh $\left(r^{2}=\right.$ $0.16-0.41)$. For the comparisons presented here, only those $\mathrm{m} / z$ that contributed to $90 \%$ of the HR-AMS UMR organic signal in any of the experiments was used to calculate the correlations. The $m / z$ values used in the UMR analysis are listed in the Supplement.

The composition of organic aerosol can also be described through the use of elemental analysis (Aiken et al., 2008). Results of such analyses are presented on a Van Krevelen diagram with axes of hydrogen to carbon $(\mathrm{H}: \mathrm{C})$ and oxygen to carbon $(\mathrm{O}: \mathrm{C})$ ratios. In general, laboratory SOA generation studies produce aerosol that is less oxidized than those found in the ambient atmosphere (Kroll and Seinfeld, 2008). However, laboratory chamber studies have also shown a wide variability in elemental ratios that are dependent on the precursor compounds used to generate the aerosol (Chhabra et al., 2010; Ng et al., 2010). Consequently, differences in the precursor compounds from different sources of BVOCs (e.g., different trees, or pre-treatment versus post-treatment emissions, or the presence of near semi-volatile plant hormones) could produce differences in biogenic SOA composition that would occupy different locations in Van Krevelen space.

Some of the baseline aerosol growth experiments had low HR-AMS signals $\left(<10 \mu \mathrm{g} \mathrm{m}^{-3}\right.$ of organic aerosol). Conse- 
Table 2. Experiment conditions. The n.r. stands for not recorded. Particle volume was calculated from SMPS measurements.

\begin{tabular}{|c|c|c|c|c|c|c|c|c|}
\hline $\begin{array}{l}\text { Experiment } \\
\text { ID }\end{array}$ & $\begin{array}{l}\text { Biogenics } \\
\text { chamber } \\
\text { RH }(\%)\end{array}$ & $\begin{array}{l}\text { Biogenics } \\
\text { chamber } \\
\text { temp }(\mathrm{K})\end{array}$ & $\begin{array}{l}\text { Aerosol } \\
\text { chamber } \\
\text { RH }(\%)\end{array}$ & $\begin{array}{l}\text { Aerosol } \\
\text { chamber } \\
\text { temp }(\mathrm{K})\end{array}$ & $\begin{array}{l}\text { Ozone at } \\
\text { experiment } \\
\text { start (ppb) }\end{array}$ & $\begin{array}{l}\text { Ozone at } \\
\text { experiment } \\
\text { end (ppb) }\end{array}$ & $\begin{array}{l}\text { Max Particle } \\
\text { volume } \\
\left(\mu \mathrm{m}^{3} \mathrm{~m}^{-3}\right)\end{array}$ & $\begin{array}{l}\text { Elemental } \\
\text { analysis }\end{array}$ \\
\hline PPo-1-Pre & n.r. & n.r. & n.r. & n.r. & 70 & n.r. & 6.24 & UMR \\
\hline PPo-1-Post & n.r. & n.r. & n.r. & n.r. & 50 & 33 & 6.33 & HR \\
\hline PPo-2-Pre & $97 \%$ & 301 & $17 \%$ & 298 & 460 & 415 & 21.33 & UMR \\
\hline PPo-2-Post & $91 \%$ & 300 & $20 \%$ & 298 & 130 & 99 & 11.64 & UMR \\
\hline PA-1-Pre & $69 \%$ & 300 & $12 \%$ & 299 & 90 & 60 & 25.76 & HR \\
\hline PA-1-Post & $79 \%$ & 300 & $12 \%$ & 298 & 130 & 107 & 8.19 & UMR \\
\hline PA-2-Pre & $88 \%$ & 300 & $19 \%$ & 298 & 255 & 174 & 3.48 & UMR \\
\hline PA-3-Pre & $96 \%$ & 299 & $26 \%$ & 296 & 126 & 90 & 2.7 & UMR \\
\hline PA-3-Post & $90 \%$ & 300 & $21 \%$ & 298 & 148 & 105 & 6.02 & UMR \\
\hline PA-4-Pre & $90 \%$ & 300 & $21 \%$ & 299 & 126 & 93 & 3.6 & UMR \\
\hline AG-1-Pre & $100 \%$ & 299 & $26 \%$ & 297 & 114 & 9 & 156.87 & HR \\
\hline AG-1-Post & $96 \%$ & 302 & $26 \%$ & 301 & 126 & 15 & 172.45 & HR \\
\hline AG-2-Pre & $96 \%$ & 304 & $29 \%$ & 302 & 116 & 5 & 17.32 & HR \\
\hline AG-2-Post & $97 \%$ & 303 & $26 \%$ & 302 & 124 & 34 & 150.33 & HR \\
\hline AG-3-Pre & $87 \%$ & 305 & $23 \%$ & 303 & 151 & 37 & 36.78 & HR \\
\hline AG-3-NC & $86 \%$ & 306 & $20 \%$ & 304 & 146 & 49 & 41.73 & HR \\
\hline TP-1-Pre & $92 \%$ & 306 & $20 \%$ & 305 & 129 & 37 & 3.24 & HR \\
\hline TP-1-Post & $97 \%$ & 305 & $25 \%$ & 304 & 129 & 26 & 123.98 & HR \\
\hline TP-2-Pre & $85 \%$ & 303 & $21 \%$ & 302 & 138 & 42 & 13.56 & HR \\
\hline TP-2-NC & $94 \%$ & 303 & $24 \%$ & 302 & 144 & 42 & 15.65 & HR \\
\hline TP-3-Pre1 & $99 \%$ & 300 & $26 \%$ & 299 & 128 & 25 & 1.78 & UMR \\
\hline TP-3-Pre2 & $97 \%$ & 300 & $32 \%$ & 299 & 123 & 3 & 2.98 & UMR \\
\hline TP-3-Post & $96 \%$ & 300 & $25 \%$ & 299 & 116 & 53 & 61.93 & $\mathrm{HR}$ \\
\hline $\mathrm{PPu}$-1-Post & $99 \%$ & 298 & $24 \%$ & 298 & 275 & 21 & 104.59 & HR \\
\hline PPu-2-Pre & $97 \%$ & 304 & $22 \%$ & 303 & 142 & 23 & 16.28 & HR \\
\hline $\mathrm{PPu}$-2-Post & $98 \%$ & 305 & $21 \%$ & 304 & 115 & 21 & 33.69 & HR \\
\hline PM-1-Pre & $96 \%$ & 303 & $20 \%$ & 302 & 195 & 29 & 4.06 & HR \\
\hline PM-1-Post & $96 \%$ & 303 & $22 \%$ & 303 & 222 & 16 & 160.78 & HR \\
\hline PM-2-Pre & $98 \%$ & 300 & $33 \%$ & 298 & 212 & 71 & 58.84 & UMR \\
\hline PM-2-Post & $95 \%$ & 300 & $26 \%$ & 298 & 109 & 37 & 118.71 & HR \\
\hline Mix-1-Pre & $87 \%$ & 306 & $20 \%$ & 305 & 136 & 17 & 5.88 & UMR \\
\hline Mix-1-Post & $85 \%$ & 306 & $18 \%$ & 304 & 140 & 6 & 133.68 & HR \\
\hline Mix-2-Pre & $82 \%$ & 303 & $17 \%$ & 302 & 125 & 15 & 21.98 & HR \\
\hline Mix-2-NC & $88 \%$ & 302 & $22 \%$ & 301 & 144 & 22 & 24.23 & HR \\
\hline
\end{tabular}

quently, the high-resolution data were screened to ensure adequate signal-to-noise, $s / n$, for further HR analysis. All elemental ratios presented from the HR analysis had a relative standard deviation less than $10 \%$. For the experiments with low $s / n$, elemental ratios of $\mathrm{O}: \mathrm{C}$ and $\mathrm{H}: \mathrm{C}$ were parameterized with UMR data, using the fractions of $m / z 44\left(f_{44}\right)$ and of $m / z 43\left(f_{43}\right)$ to the total organic signal as described by Aiken et al. (2008) and Ng et al. (2011), respectively. The approach used to calculate elemental ratios (UMR vs. HR) for each experiment is summarized in Table 2 along with other important experimental conditions. Substantial revisions to the Aiken et al. (2008) approach to elemental analysis have recently been proposed by Canagaratna et al. (2015). These revisions have not been incorporated into this analysis. A major motivation for performing elemental analysis in this work was to make comparisons with previously published results, which used the earlier methods. Another objective was to compare results between the different experiments conducted here; the new approach will affect all ratios similarly and thus will not influence the conclusions from these comparisons. Other technical considerations related to the HR data analysis are described in more detail in the Supplement.

We cannot rule out the presence of $\mathrm{NO}_{\mathrm{x}}$ in the reaction chamber because the plant chamber contained saplings potted in soil - microbial activity in soil can be a source of $\mathrm{NO}_{\mathrm{x}}$. While $\mathrm{NO}_{\mathrm{x}}$ was not measured directly, we could observe that 

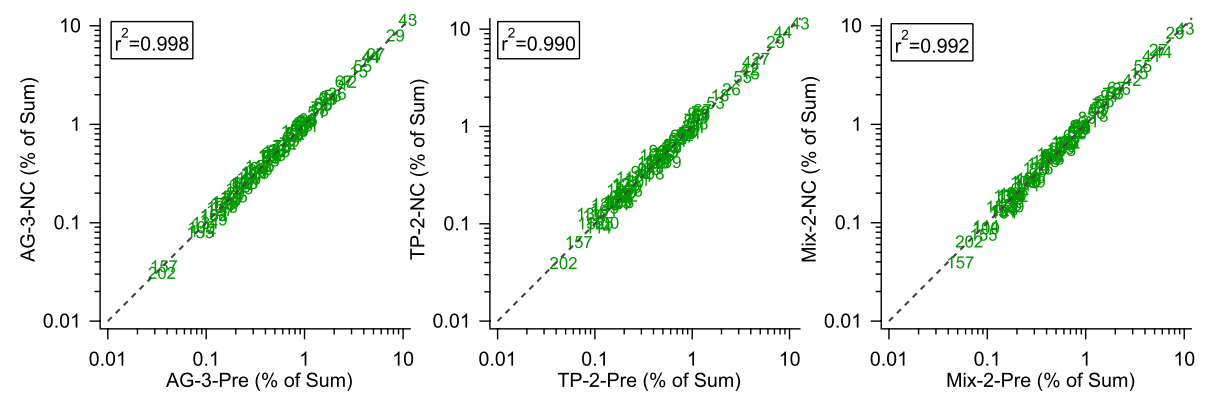

Figure 1. Scatter plots comparing the normalized spectra of all three paired pre-treatment/negative-control experiments. The markers denote the $m / z$. Only the 89 UMR $m / z$ signals used in the correlation analyses are plotted. The $x$ axis is the percent contribution to total organic mass for the pre-treatment experiment and the $y$ axis is the percent contribution to total organic mass for the paired negative control experiments. The dashed gray 1:1 lines are shown for reference. AG-3 is an Abies grandis experiment. TP-2 is a Thuja plicata experiment, Mix-2 is a mixed Abies grandis and Pseudotsuga menziesii experiment. Correlations $\left(r^{2}\right)$ between the negative control spectra and the pre-treatment spectra are shown in the boxes on each plot.

the contribution of nitrogen-containing peaks to total organic signal was low $-\mathrm{N}: \mathrm{C}$ ratios ranged from 0.004 to 0.011 . Consequently, the nitrogen-containing signals were not the focus of the analysis presented in this paper.

\section{Results and discussion}

Our analysis of the SOA composition in these experiments show definite inter- and intra-species variability, but the differences are generally subtle. In this section, we first present the paired pre-treatment and negative control experiments to demonstrate the reproducibility of the chamber system and provide context for the variability that was observed in other experiments. Next, a summary of all experiments is presented with a discussion of the inter- and intra-species variation, followed by a discussion of the post-treatment aerosol spectra. In this section, we present the first aerosol mass spectra generated from SOA produced via the gas-phase oxidation of the plant hormone, MeJA. Finally, we present results of the SOA elemental analysis using a Van Krevelen plot and discuss the inter-species variability along with implications for stress effects on SOA composition.

\subsection{Negative controls}

Three sets of paired pre-treatment/negative control experiments were performed for which AMS measurements are available - one with grand fir (Abies grandis), one with western redcedar (Thuja plicata), and one with a mix of grand fir (Abies grandis) and Douglas fir (Pseudotsuga menziesii). Negative controls refer to experiments where the plants were sprayed with water instead of the MeJA solution. Scatter plots comparing the normalized UMR organic spectra between the pre-treatment SOA and the corresponding paired negative control SOA are shown in Fig. 1. The signal at $\mathrm{m} / z 28$ was removed to avoid air interferences in the UMR spectra comparisons. The coefficient of determination $\left(r^{2}\right)$ for each comparison is shown, calculated from the square of the Pearson product moment correlation coefficient. All paired negative control experiments were very similar, with $r^{2}$ greater than or equal to 0.990 . The reproducibility of the high correlations between these paired experiments suggests that any correlations less than 0.99 that were observed in other experiments do truly reflect differences in SOA mass spectra. Based on these results, we considered any correlations lower than 0.90 to indicate potentially noteworthy differences between SOA mass spectra.

\subsection{UMR comparisons}

Correlations $\left(r^{2}\right)$ comparing SOA organic UMR spectra from all biogenic aerosol growth experiments are summarized in Fig. 2. Correlations ranged from 0.503 to 0.999 . In general, the pre-treatment aerosol mass spectra from all tree types had higher correlation values with respect to each other than they did with respect to post-treatment aerosol mass spectra. One pre-treatment experiment, AG-1-Pre (no. 9), stands out clearly with lower correlation values when compared to all other spectra. During this experiment, plants may have been exposed to an unidentified stress before transport to the laboratory (Faiola et al., 2015). This pre-treatment experiment will be referred to as the unidentified stress (UNID) stress experiment and will be discussed in detail in a later section. Other than the AG-1-Pre spectrum, all other pre-treatment SOA spectra had correlations ranging from 0.806 to 0.997 when compared to each other across all tree types.

Most of the weakest correlations (excluding the AG-1-Pre spectrum) were found between comparisons that included the 2013 post-treatment experiments (nos. 21-30 in Fig. 2). Specifically, the following experiments had the lowest correlations when compared to other SOA spectra: AG-2-Post (no. 23), TP-1-Post (no. 24), TP-3-Post (no. 25), PM-1-Post (no. 28), PM-2-Post (no. 29), and Mix-1-Post (no. 30). This list includes all the experiments where the MeJA treatment and 


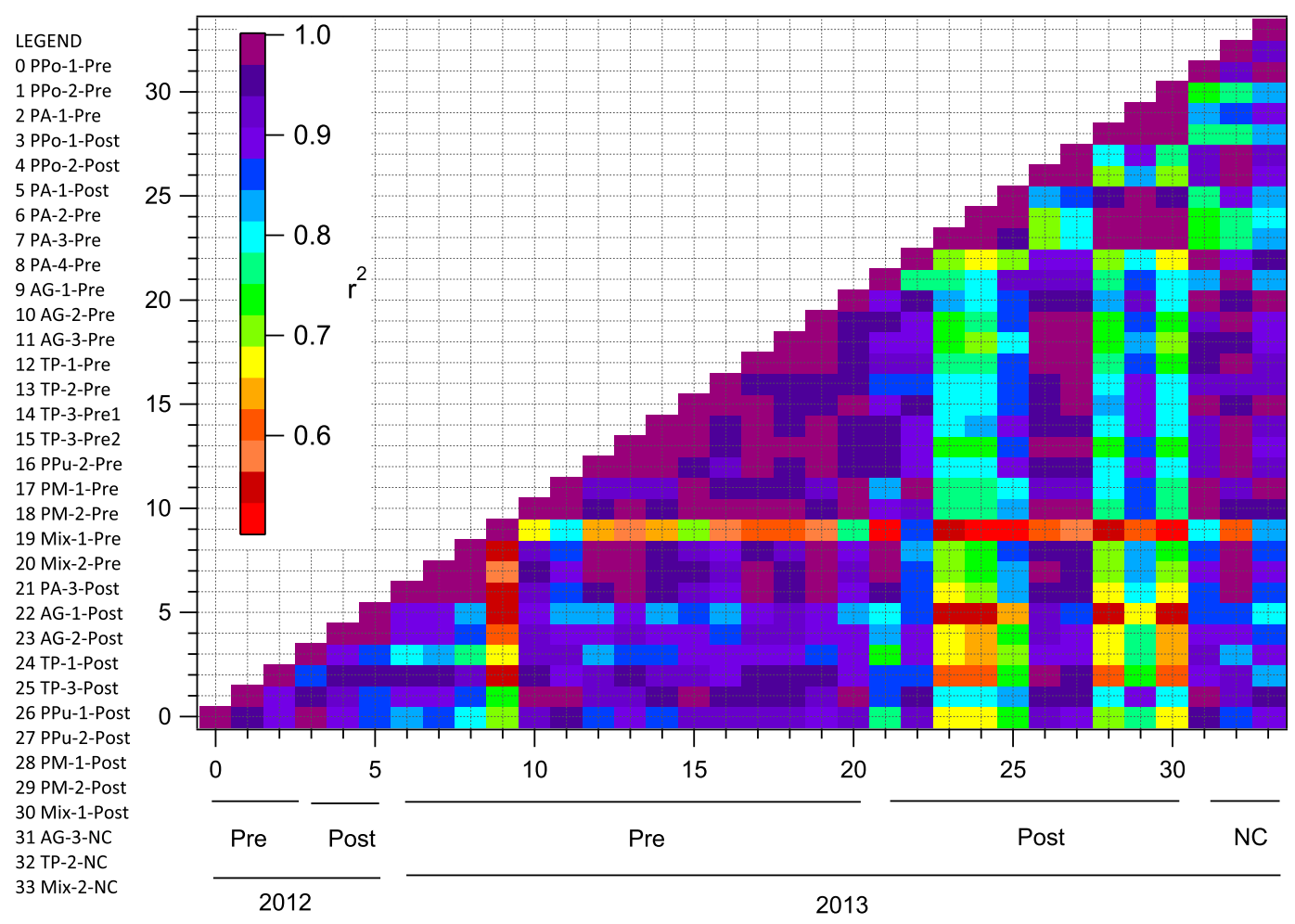

Figure 2. Summary of all comparisons between biogenic SOA spectra. Each number on the $x$ and $y$ axes refers to a single SOA growth experiment. The legend provides a key to match the axis number with its corresponding experiment ID. Details of each experiment are listed by experiment ID in Tables 1 and 2. The color scale denotes the strength of correlation between the two spectra. Due to air interferences, $\mathrm{m} / \mathrm{z} 28$ was removed from the spectra for all comparisons. The figure was organized by year followed by experiment type (pre-treatment, post-treatment, negative control) followed by tree type. NC is negative control.

the aerosol growth experiment occurred on the same day (Table 1). In contrast, when these six aerosol spectra were compared to one another, each comparison had $r^{2}$ greater than or equal to 0.95 . This suggests that the MeJA and its oxidation products may have contributed substantially to SOA formation. This hypothesis and its environmental implications are explored in detail in a later section on MeJA SOA.

To further investigate trends in the SOA spectra correlations, all comparisons were classified by the type of comparison and binned into six different ranges of correlation values: <0.6000, 0.6000-0.6999, 0.7000-0.7999, 0.8000$0.8999,0.9000-0.9499$, and $0.9500-0.9999$. The results of this analysis are presented in Fig. 3. The top bar in the figure shows the results from all types of biogenic SOA comparisons using real plant emission as the VOC precursor for SOA formation ( $N=561$ total comparisons). This classification did not include any comparisons with the MeJA standard SOA spectrum. Nearly $50 \%$ of all comparisons with biogenic SOA had an $r^{2}$ greater than or equal to 0.90 . The rest of the comparison types were organized reading top to bottom from the highest to the lowest number of correlations that fell within the 0.9500-0.9999 correlation bin. Comparisons between experiments performed different years and compar- isons with the standard MeJA spectrum are discussed in the Supplement (Fig. S2).

All three comparisons of the paired pre-treatment/negative control SOA spectra were in the highest correlation bin with an $r^{2}$ greater than or equal to 0.95 . The fifteen comparisons between the post-treatment SOA spectra where the MeJA treatment occurred the same day as the SOA growth experiment (SD, PostT) were all greater than or equal to 0.90 . The pre-treatment SOA comparisons were more heavily weighted toward the higher correlation values than the all comparisons category, with nearly $80 \%$ of the $r^{2}$ values greater than or equal to 0.90 . Additionally, the pre-treatment SOA spectra were more similar to one another than the post-treatment spectra were to one another. This suggests there was more variability in VOC emissions post-treatment than there was pre-treatment between the different tree types. The negative control spectra tended to be more similar to the pre-treatment SOA than the post-treatment SOA with nearly $80 \%$ of comparisons with $r^{2}$ greater than or equal to 0.90 for the former and only $\sim 30 \%$ of comparisons with $r^{2}$ greater than or equal to 0.90 for the latter. SOA spectra from the same tree type were more heavily weighted toward the higher correlation bins than SOA spectra generated from different tree types. 


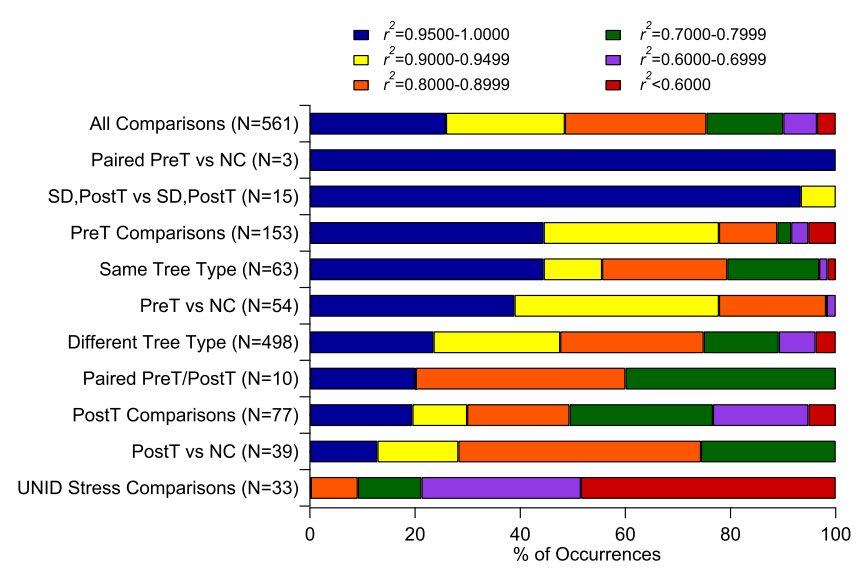

Figure 3. Distribution of correlations classified by type of comparison. $x$ axis is the $\%$ of total occurrences within a given correlation range for each experiment classification. Each horizontal bar denotes the type of comparison where the $N$ value in parentheses refers to the total number of comparisons within that classification. PreT is pre-treatment; PostT is post-treatment; NC is negative control; SD,PostT is post-treatment where treatment and SOA growth experiment occurred on the same day; UNID stress is unidentified stress.

Thirteen paired pre-treatment/post-treatment experiments were performed. Six of these had GC-MS-FID data available to investigate whether or not a plant response to the stress treatment had occurred. For several of the intended pre-treatment/post-treatment comparisons, there were no differences in the BVOC profile between the pre- and posttreatment experiment. These paired experiments were excluded from our comparisons after also verifying that the stress treatment had not produced any significant differences in the SOA mass spectra (PPo-2, $r^{2}=0.92$; $\mathrm{PPu}-2$, $r^{2}=0.98$; PA-3, $r^{2}=0.97$ ). All other pre-treatment/posttreatment comparisons were included in the analysis even if the BVOC profile only changed minimally after treatment (PPo-1) or if there were confounding winter dormancy effects on emissions (PA-1). All of the comparisons without GC data to confirm plant stress response were included in the analysis. Eight of the 10 remaining pre-treatment/posttreatment comparisons had $r^{2}$ between 0.7 and 0.8999, substantially lower than the negative control spectra comparisons. This suggests there were small, but possibly significant, differences between the SOA generated under the baseline emissions scenario and the SOA generated under the herbivore-stress emissions scenario. A potential plant stress AMS marker in the post-treatment SOA is discussed further in Sect. 3.4.2.

The weakest correlations between biogenic SOA spectra (excluding the MeJA single-component standard spectra comparisons) were observed for comparisons with the UNID stress SOA from experiment AG-1-Pre (no. 9). All SOA spectra comparisons with the UNID stress spectrum had correlations less than 0.90 and nearly $80 \%$ of the comparisons had $r^{2}$ less than 0.70 . Due to the dissimilar nature of this SOA spectrum relative to others, we have included a detailed description of the spectral characteristics of this SOA in a later section (Sect. 3.4).

\subsection{Post-treatment aerosol mass spectra}

Thirteen post-treatment SOA experiments were completed for this study. Of those, three were performed in 2012 with the exogenous MeJA treatment. The PPo- 1 experiment exhibited small, likely insignificant, differences between the pre- and post-treatment SOA that could have been due to natural variation in plant emissions. The BVOC profile indicated that any stress response was weak if it existed at all. The other two experiments performed in 2012 may have had a confounding stress effect due to pulling the plants out of dormancy. For these reasons, the 2012 post-treatment experiments will not be the focus of this discussion of posttreatment SOA here. Of the 10 post-treatment SOA experiments performed in 2013 with the foliar MeJA application, four were performed the day after treatment and six were performed the same day as treatment.

The four experiments that were performed the day after MeJA treatment were PPu-1-Post, PPu-2-Post, AG-1-Post, and PA-3-Post. Based on the BVOC profiles, none of the post-treatment experiments where the treatment was performed on a different day than the aerosol growth experiment would work as good candidates for identifying a biogenic stress SOA marker in the AMS spectra. The AG-1-Post SOA spectrum shows confounding effects on the SOA spectra from an apparent unidentified stress, as discussed in Section 3.4. The PPu-1-Post and PPu-2-Post both appear to be representative of a stress condition for Picea pungens based on the BVOC profiles presented in Faiola et al. (2015). The stress response for the $\mathrm{PPu}-1$ experiment in particular was very high. However, the PPu-1-Pre experiment did not produce enough SOA mass to perform AMS analysis, so there is no baseline Picea pungens SOA spectra for comparison. The BVOC results from the PPu-2-Pre experiment suggest these plants may also have been stressed before being brought into the laboratory; their BVOC profile closely resembled the post-treatment Picea pungens BVOC profile from the previous experiment. So, no baseline Picea pungens SOA spectra were acquired for comparison with the post-treatment SOA spectra for these two experiments. Finally, no stress response was observed during the PA-3 experiment based on the BVOC profile. Consequently, this post-treatment SOA spectrum could not be used to identify a stress biogenic SOA marker either.

The remaining six post-treatment SOA spectra were AG2-Post, PM-1-Post, PM-2-Post, TP-1-Post, TP-3-Post, and Mix-1-Post. Where BVOC data were available (PM-2 and TP-3), it suggested there was an identifiable plant stress response due to the foliar MeJA stress treatment (Faiola et al., 
2015). These six spectra also stand out distinctly on the correlation summary figure because they had lower correlations with other spectra than observed for most of the other SOA spectra comparisons (Fig. 2). However, the influence of the MeJA and its oxidation products needs to be accounted for when interpreting these spectra. A discussion of these results is provided in the next section.

\subsubsection{Methyl jasmonate SOA}

The aerosol mass spectrum of SOA generated from the oxidation of the single-component MeJA standard is shown in Fig. 4. To the authors' knowledge, this is the first description of SOA generated from the plant hormone, MeJA, from ozone-initiated gas-phase oxidation. The dominant fragments in the normalized mass spectrum were $m / z$ 28, 29, and 44. The standard MeJA SOA had more of the highly oxidized $\mathrm{m} / \mathrm{z} 44$ and less $\mathrm{m} / \mathrm{z} 43$ than observed in typical biogenic SOA generated from chamber experiments. Additionally, there were small, but observable, peaks at $m / z 131$ and $m / z 157$ that were not typical of the other biogenic SOA spectra generated in the work presented here. The lowest correlations between all SOA spectra acquired throughout these experiments were observed between biogenic SOA generated from real plant emissions and SOA derived from the oxidation of the MeJA single-component standard. This is shown in the bottom three horizontal bars on Fig. S2 in the Supplement. The most similar spectra to the MeJA standard were those from the post-treatment SOA where treatment was applied the same day as the SOA growth experiment (SD, PostT). However, even these correlations were all less than or equal to 0.8999 . All other comparisons between biogenic SOA spectra and single-component MeJA standard spectra had $r^{2}$ less than 0.80 .

The possible influence of MeJA and its oxidation products on SOA composition could have significant atmospheric implications because plant hormones can be emitted from forests at rates as high as monoterpenoids when plants experience stressed conditions in the natural environment (Karl et al., 2008). For the experiments where the MeJA foliar application occurred on the same day as the aerosol growth experiments (referred to herein as same-day experiments), the estimated amount of MeJA vapor transported to the aerosol growth chamber was between 30 and $70 \%$ of the total monoterpenoid concentrations. This value was estimated based on the saturation vapor pressure of MeJA, with the range reflecting variations in monoterpenoid emission rates from experiment to experiment.

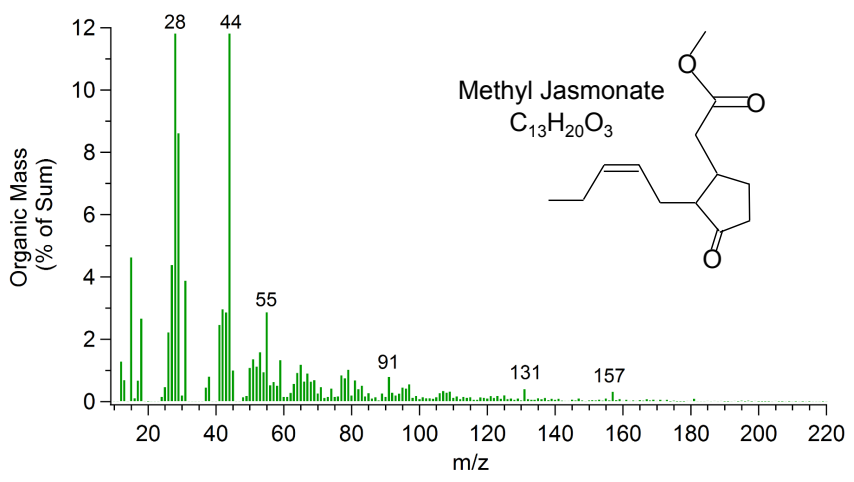

Figure 4. Normalized mass spectra of SOA generated from the oxidation of a MeJA standard. The $x$ axis shows the $m / z$ value and the $y$ axis denotes the percent contribution of each $\mathrm{m} / z$ to the total organic mass. The chemical structure and molecular formula of MeJA is shown on the figure.

\subsubsection{Corrected 2013 same-day post-treatment SOA}

The relative contribution of MeJA to the six same-day posttreatment SOA spectra was estimated by generating a series of linear combinations of different relative amounts of the normalized pre-treatment SOA spectra and the normalized MeJA standard SOA spectra. For each series, an optimized linear combination was determined based on identifying the combination spectra that had the strongest correlation with the paired post-treatment SOA spectra. The results of this analysis for all six same-day experiments are presented in Fig. 5. In each of the six experiments, the optimized linear addition spectrum occurred when the contribution of the pretreatment spectrum was between 40 and $60 \%$ of the combination spectrum. Thus, MeJA and its oxidation products were estimated to contribute between 60 and $40 \%$ of the SOA mass in the same-day post-treatment spectra. The optimized combination spectrum was then subtracted from the normalized post-treatment spectra to define a residual spectrum for each experiment. This residual should be more representative of the influence of stress-induced emissions on post-treatment spectra, having removed the presumed direct effect of the MeJA present.

All six of these residual spectra are shown in Fig. 6. Only the positive values are shown to focus on the $m / z$ fragments that were remaining after subtracting off the optimized linear addition of the paired pre-treatment and MeJA standard spectra. The residual spectra were generally very similar to one another with $r^{2}>0.90$ for most comparisons. The residual TP-3-Post was an exception to this with correlations ranging from 0.32 to 0.70 with the other residual spectra. The strongest contributions across the residual spectra were at $m / z 26,27,29,31,57,58,59,71$, and 83. Many of these are consistent with the most enhanced fragments described earlier from the stress response spectra comparing the paired AG-1-Pre and AG-1-Post spectra $(m / z, 26,27,31$, and 58). 

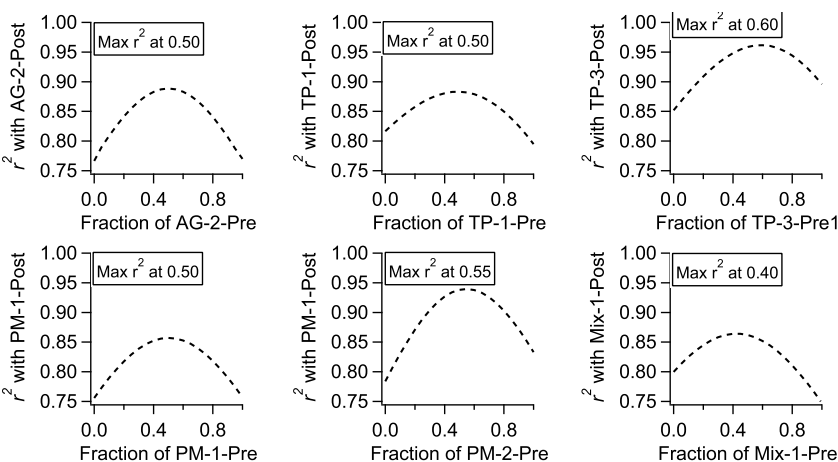

Figure 5. Results from the linear addition optimization for all six experiments where the post-treatment aerosol growth experiment was performed the same day the foliar MeJA treatment was applied. The $x$ axis denotes the fraction of the pre-treatment experiment that was included in the linear addition of the pre-treatment and MeJA standard SOA spectra. The $y$ axis is the correlation of the linear addition spectra with the paired post-treatment SOA spectra. The fraction of pre-treatment SOA included in the linear addition spectra that produced the highest correlation with the paired post-treatment is shown in the box on each graph.

The AG-1-Post experiment was conducted the day following foliar MeJA treatment rather than on the same day as MeJA, so the contribution of MeJA and its oxidation products to SOA mass should have been minimal. This further supports the hypothesis that enhanced $m / z, 31$ and 58 are associated with a biogenic stress response. It is also worth noting that $m / z 29$ was the largest fragment in each of the six residual spectra, and specifically that the $\mathrm{HR}$ ion $\mathrm{C}_{2} \mathrm{H}_{5}^{+}$at $m / z 29$ was increased more significantly than the other major HR ion at $m / z 29, \mathrm{CHO}^{+}$. Other larger $\mathrm{HR}$ ions found prominently in the residual spectra were $\mathrm{C}_{3} \mathrm{H}_{5} \mathrm{O}^{+}(\mathrm{m} / z 57), \mathrm{C}_{2} \mathrm{H}_{3} \mathrm{O}_{2}^{+}$and $\mathrm{C}_{3} \mathrm{H}_{7} \mathrm{O}^{+}\left(m / z\right.$ 59), $\mathrm{C}_{3} \mathrm{H}_{3} \mathrm{O}_{2}^{+}$and $\mathrm{C}_{4} \mathrm{H}_{7} \mathrm{O}^{+}(m / z$ 71), and $\mathrm{C}_{4} \mathrm{H}_{3} \mathrm{O}_{2}^{+}, \mathrm{C}_{5} \mathrm{H}_{7} \mathrm{O}^{+}$, and $\mathrm{C}_{6} \mathrm{H}_{11}^{+}(m / z$ 83). At $m / z$ 83, the $\mathrm{C}_{5} \mathrm{H}_{7} \mathrm{O}^{+}$was the most enhanced $\mathrm{HR}$ ion. The potential enhancement of these ions due to biogenic stress response merits further targeted investigation.

\subsection{A closer look at Abies grandis (grand fir) SOA}

Three paired sets of aerosol growth experiments were performed with Abies grandis emissions: two pretreatment/foliar MeJA treatment experiments (AG-1 and AG-2) and one pre-treatment/negative control experiment (AG-3). The negative control results were presented in Sect. 3.1. BVOC measurements were collected during aerosol growth chamber loading for AG-1, but not for the other two sets of experiments due to a GC instrument malfunction. In the companion paper, we hypothesized that the Abies grandis saplings used in experiment AG-1 had been exposed to an unidentified external stress outdoors where they were being stored before being transported to the laboratory chamber (Faiola et al., 2015). Consequently,

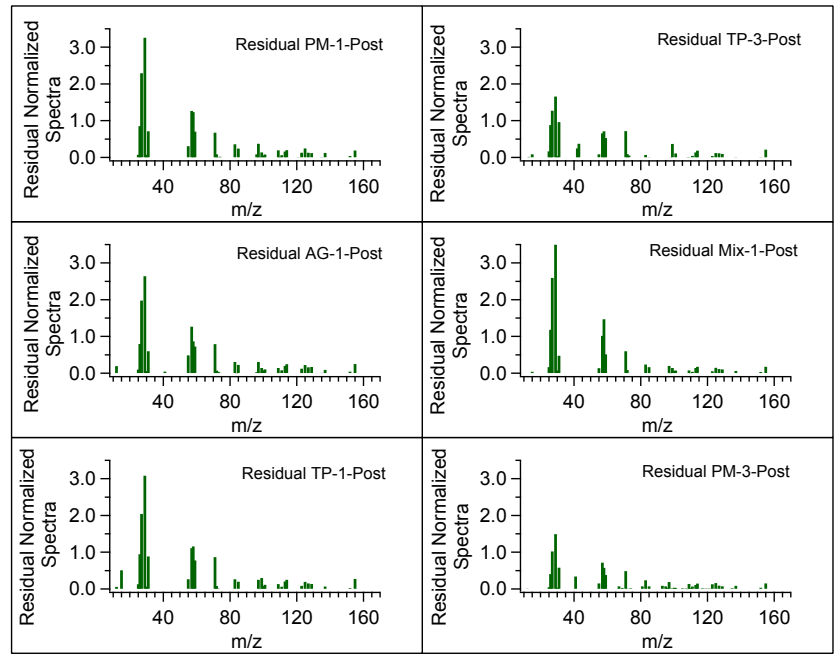

Figure 6. Residual stress spectra calculated by subtracting the optimized linear addition of the paired baseline + MeJA standard spectra from the post-treatment stress spectra. The $x$ axis is the $m / z$ value and the $y$ axis is the residual. Negative residuals have been removed to focus on the enhanced $m / z$ peaks.

this is one of the only experiments where emissions actually decreased after MeJA treatment relative to the pre-treatment value. This experiment provided an opportunity to investigate the effects of a naturally elicited stressor on BVOC emissions and biogenic SOA composition in contrast to stress elicited from plant hormone application. Furthermore, despite the presence of an external stressor, the MeJA treatment still induced emissions of 1,8-cineol and terpinolene allowing us to investigate the impact of multiple stressors. This scenario is representative of an environmentally relevant case because the presence of multiple stressors in the natural environment is likely the rule rather than the exception. The BVOC profiles during aerosol chamber loading for experiment AG-1 are shown in Supplement (Fig. S3).

The correlation between the AG-2-Pre SOA mass spectrum and the AG-3-Pre spectrum was very strong, with an $r^{2}$ of 0.97. The AG-1-Pre SOA spectrum was less similar to the other two Abies grandis pre-treatment SOA spectra with $r^{2}$ values of 0.66 (vs. AG-2-Pre) and 0.80 (vs. AG-3-Pre). The aerosol mass spectra for AG-1-Pre, AG-2-Pre, and AG2-Post are shown in Fig. 7 to highlight some of the $m / z$ contributing to the differences between the SOA spectra. The AG-1-Pre SOA spectrum has a significant cluster of peaks present around $m / z 200$ that were not observed in any other aerosol mass spectra including the other SOA spectra produced from Abies grandis emissions. This evidence further supports the hypothesis that the AG-1-Pre spectra was not representative of a typical Abies grandis SOA baseline and that these plants had been exposed to an unidentified stressor. The AG-2-Pre spectrum is more representative of a typical 

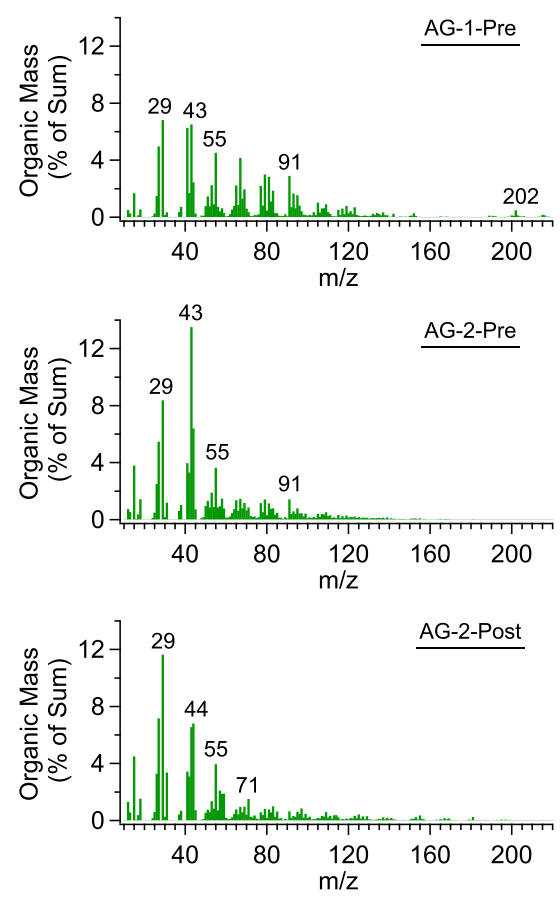

Figure 7. Organic mass spectra of SOA produced from the first Abies grandis pre-treatment experiment (AG-1-Pre), the second Abies grandis pre-treatment experiment (AG-2-Pre), and the second Abies grandis post-treatment experiment (AG-2-Post). The AG1-Pre spectrum represents a naturally elicited stress condition, the AG-2-Pre spectrum represents a typical baseline condition, and the AG-2-Post represents a typical post-treatment condition after MeJA plant hormone application.

baseline SOA spectrum. The mass spectrum of SOA generated from alpha-pinene dark ozonolysis is shown in the Supplement (Fig. S4; Bahreini et al., 2005) for comparison with the baseline biogenic SOA spectrum presented in this paper.

To investigate differences in the relative $\mathrm{m} / \mathrm{z}$ enhancements and reductions generated under the unidentified stress condition and the MeJA stress condition, AG-2-Pre was selected to use as a typical Abies grandis baseline spectrum for comparison. A stress response plot was generated for both the unidentified stress effect and MeJA stress effect (Fig. 8). The unidentified stress response was calculated by subtracting the normalized spectrum of the AG-2-Pre experiment (baseline Abies grandis SOA) from the normalized spectrum of the AG-1-Pre experiment (unidentified stress SOA). The MeJA stress response was calculated by subtracting the normalized spectra of the same AG-2-Pre experiment (baseline Abies grandis SOA) from its paired post-treatment MeJA stress experiment, AG-2-Post (MeJA post-treatment SOA). The changes to the $m / z$ profile were substantially different between the two stress scenarios. The MeJA SOA stress response spectrum demonstrated the most enhanced $\mathrm{m} / \mathrm{z}$ values at $15,26,27,29,31,57,58,59,71$, and 97. The relative contribution of $m / z 43$ was reduced. Recall that these

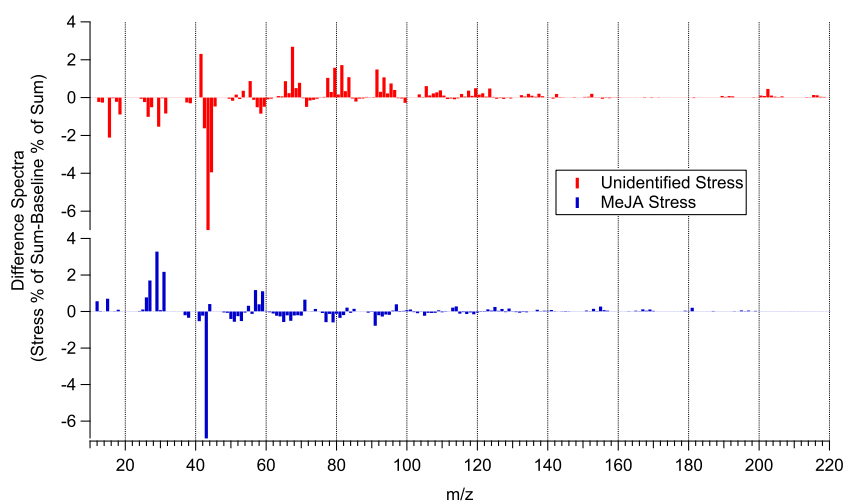

Figure 8. Stress response spectra comparing the effects of two different types of stress - an unidentified stress (red) and a MeJA treatment (blue). The $x$ axis shows the $m / z$ values and the $y$ axis denotes the difference between the normalized stress spectrum and the normalized baseline spectrum.

spectra have been normalized to the sum of total organics so a negative value in the stress response spectra does not necessarily mean that the fragment was inhibited. Rather, it demonstrates only that the relative contribution to the total has been reduced. The fragment at $m / z 43$ is frequently the highest organic fragment in chamber SOA (Chhabra et al., 2010); therefore, it is not unexpected that any increases in other fragments will produce a decrease in the relative contribution of $m / z$ 43. The fragments most enhanced in the unidentified stress response spectrum were different and included 41, 65-69, 77, 79, 81, 91, 93, 95, 105, 109, 117, 119, and 202.

The relative enhancement of most of these $m / z$ values in the unidentified stress response spectrum could be explained by the partitioning of less oxidized compounds. For example, the two $\mathrm{m} / \mathrm{z}$ series $77,79,81$ and $91,93,95$ are due to enhancements of the HR ions $\mathrm{C}_{6} \mathrm{H}_{5}^{+}, \mathrm{C}_{6} \mathrm{H}_{7}^{+}, \mathrm{C}_{6} \mathrm{H}_{9}^{+}$and $\mathrm{C}_{7} \mathrm{H}_{7}^{+}, \mathrm{C}_{7} \mathrm{H}_{9}^{+}, \mathrm{C}_{7} \mathrm{H}_{11}^{+}$, respectively. Compare this to the most enhanced $\mathrm{HR}$ ions in the MeJA stress spectrum, which included $\mathrm{CHO}^{+}, \mathrm{C}_{2} \mathrm{H}_{5}^{+}, \mathrm{CH}_{3} \mathrm{O}^{+}, \mathrm{C}_{2} \mathrm{HO}_{2}^{+}, \mathrm{C}_{3} \mathrm{H}_{5} \mathrm{O}^{+}, \mathrm{C}_{4} \mathrm{H}_{9}^{+}$, $\mathrm{C}_{2} \mathrm{H}_{2} \mathrm{O}_{2}^{+}, \mathrm{C}_{3} \mathrm{H}_{6} \mathrm{O}^{+}, \mathrm{C}_{2} \mathrm{H}_{3} \mathrm{O}_{2}^{+}, \mathrm{C}_{3} \mathrm{H}_{7} \mathrm{O}^{+} . \mathrm{C}_{3} \mathrm{H}_{3} \mathrm{O}_{2}^{+}, \mathrm{C}_{4} \mathrm{H}_{7} \mathrm{O}^{+}$, $\mathrm{C}_{5} \mathrm{H}_{5} \mathrm{O}_{2}^{+}, \mathrm{C}_{6} \mathrm{H}_{9} \mathrm{O}^{+}$, and $\mathrm{C}_{7} \mathrm{H}_{13}^{+}$. This list contains many more oxidized fragments than the enhanced HR ions in the unidentified stress response spectrum.

The weaker presence of oxidized HR ions in the unidentified stress SOA spectra could be the result of two possibilities or, possibly more likely, a combination of the two explanations. One explanation is the unidentified stress-induced emissions of large hydrocarbons, which produced a higher proportion of larger, less oxidized fragments in the spectra. This cause is suggested by the cluster of peaks greater than $m / z$ 200, particularly at $m / z 202$, in the AG-1-Pre spectrum that were not observed in any of the other spectra. The HR ion identified here was $\mathrm{C}_{16} \mathrm{H}_{10}^{+}$, a large un-oxidized fragment that could have originated from a large stress-induced hydro- 
carbon BVOC emission. The compounds that contributed to these large $m / z$ fragments were not detected by the GC system so they cannot be positively identified here. However, large 16-carbon and 18-carbon compounds have been identified following herbivory stress in other studies (De Boer et al., 2004; Mentel et al., 2013).

Another possibility is that the amount of ozone added to the chamber was not sufficient to fully oxidize these particles to the same extent as other experiments because the plant VOC emissions were so high. In all, $114 \mathrm{ppb}$ of ozone was added at the start of the experiment and it had fallen to $9 \mathrm{ppb}$ by the end (Table 2). With the high organic particle loadings generated in this experiment $\left(>500 \mu \mathrm{g} \mathrm{m}^{-3}\right)$ it is possible that some of these larger emissions and their oxidation products were able to partition to the particle phase in a less oxidized state than would normally occur under lower mass loadings (Kroll and Seinfeld, 2008). Thus, the higher emissions generated a large amount of overall organic particle mass, and the combination of the presence of larger, less volatile emissions (and their oxidation products) and an oxidant-limited system promoted the partitioning of less oxidized components to the particle phase.

The correlations between the two paired pretreatment/post-treatment Abies grandis SOA spectra were 0.86 and 0.77 for AG-1 and AG-2, respectively (Fig. 2). Thus, despite the presence of an unidentified stressor under pre-treatment conditions, the stress treatment still produced some small differences between the pre-treatment and post-treatment SOA spectra in the AG-1 experiment. This is consistent with the BVOC emission profile where emissions of 1,8-cineol were induced after treatment and the relative contribution of beta-myrcene, limonene, and terpinolene increased (Fig. S3, in the Supplement). Five of the top 10 most enhanced fragments between the AG-1-Post and AG-1-Pre spectra were also observed in the top 10 most enhanced fragments between the AG-2-Post and AG-2-Pre spectra: $m / z 15,26,27,31$, and 58. The dominant HR ions corresponding to $m / z 15,26$, and 27 were $\mathrm{CH}_{3}^{+}, \mathrm{C}_{2} \mathrm{H}_{2}^{+}$, and $\mathrm{C}_{2} \mathrm{H}_{3}^{+}$. These ions are not very specific and could be generated from many organic compounds, so it is unlikely that they alone will provide help in identification of an AMS mass spectral biotic stress SOA "marker". The dominant HR ions at $m / z 31$ and 58 were $\mathrm{CH}_{3} \mathrm{O}^{+}, \mathrm{C}_{2} \mathrm{H}_{2} \mathrm{O}_{2}^{+}, \mathrm{C}_{3} \mathrm{H}_{6} \mathrm{O}^{+}$. These ions could provide a little more insight into precursors contributing to their presence in the SOA spectra, and could possibly be the start to identifying AMS markers for biogenic stress SOA. This will be discussed further in the following sections while looking at more examples of the post-treatment SOA spectra in detail.

\subsection{Elemental analysis}

A summary of the elemental analysis results for all pretreatment SOA and negative control SOA is shown in Fig. 9a. This figure illustrates the inter-plant variation in biogenic
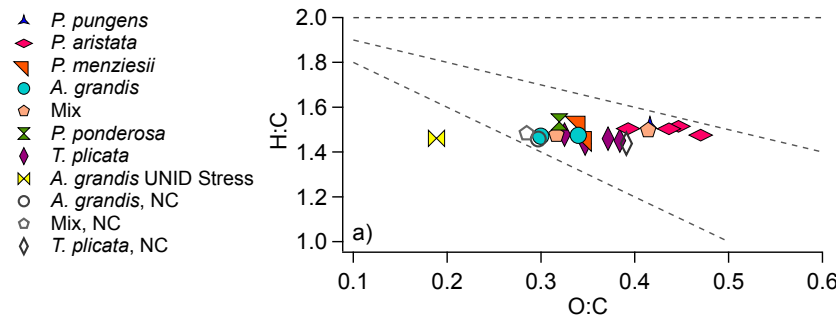

$\nabla$ PM-PreT

PM-PostT

- AG-PreT

AG-PostT

Mix-PreT

Mix-PostT

TP-PreT

TP-PostT

$\bowtie$ AG-PreT, UNID Stress

AG-PostT, UNID + MeJA

* MeJA Std.

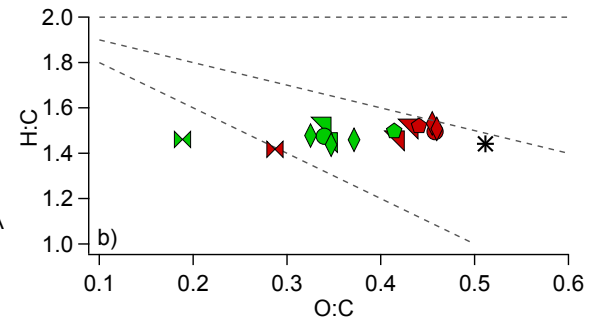

Figure 9. (a) Summary of the elemental analysis results from all pre-treatment SOA and negative control SOA. The pre-treatment experiment, AG-1-Pre, is labeled as an unidentified stress (UNID stress) experiment. NC is negative control. (b) Summary of elemental analysis results from all experiments with paired pretreatment/post-treatment SOA where a MeJA plant stress response was observed. Green markers denote pre-treatment SOA. Red markers denote post-treatment SOA. The black asterisk illustrates the results from the MeJA single-component standard SOA. The dashed lines are commonly included on Van Krevelen plots to indicate slopes of $0,-1$, and -2 , and are included here to put results in context with previous work.

SOA composition. One clear outlier was the SOA generated in experiment AG-1-Pre - the unidentified stress (UNID stress) experiment that was discussed previously. All H : C ratios were similar $(\sim 1.5)$ throughout the pre-treatment experiments. This is consistent with expected $\mathrm{H}: \mathrm{C}$ ratios for SOA generated from biogenic precursors (Chhabra et al., 2010). In contrast, the $\mathrm{O}: \mathrm{C}$ ratios varied between different tree types. In fact, the elemental analysis results demonstrated a higher level of variability between pre-treatment SOA than was expected from the UMR correlation coefficient analysis. This could partially be caused by the exclusion of $m / z 28$ in the UMR analysis. The $\mathrm{CO}^{+}$ion was accounted for in the elemental analysis but not in the UMR analysis. The contribution from organics at $\mathrm{m} / \mathrm{z} 28$ was a substantial fraction of the total signal and is commonly estimated to be around the same magnitude as $m / z 44$ - a significant peak for all of these spectra contributing between 4 and $10 \%$ of total organic signal.

Most pre-treatment SOA had an $\mathrm{O}: \mathrm{C}$ within the range of 0.3-0.38. However, there were some exceptions. Specifically, the Pinus aristata SOA had a higher O:C on average than other pre-treatment biogenic SOA generated from emissions of other tree types with $\mathrm{O}: \mathrm{C}$ ranging from 0.39 to 0.47 . Similarly, one pre-treatment Picea pungens experiment and one pre-treatment mix experiment generated biogenic SOA with 
higher $\mathrm{O}: \mathrm{C}$ values than the average. The pre-treatment SOA from the Picea pungens emissions could have been more representative of a stress condition based on the BVOC emission profile - stress emissions of 1,8-cineol and beta-ocimene were measured (Faiola et al., 2015). A second pre-treatment mix experiment was performed and produced SOA with a much lower $\mathrm{O}: \mathrm{C}$ than the first, so the high $\mathrm{O}: \mathrm{C}$ results from the pre-treatment mix emissions were not reproducible. Two of the three negative control SOA had some of the lowest $\mathrm{O}: \mathrm{C}$ ratios that were measured (excluding the UNID stress experiment). The Thuja plicata negative control had substantially higher $\mathrm{O}: \mathrm{C}$ than the others, but it was very similar to the other pre-treatment Thuja plicata experiments.

A summary of the elemental analysis results from all paired pre- and post-treatment experiments where a plant stress response was observed is presented in Fig. 9b. The pre-treatment SOA that had a paired post-treatment experiment where a stress response was observed had $\mathrm{O}: \mathrm{C}$ that ranged from 0.32 to 0.41 (excluding the unidentified stress experiment) or 0.32 to 0.37 if the possible mix SOA outlier is excluded as well. The paired post-treatment SOA had O : C that ranged from 0.42 to 0.46 . For all experiments, the MeJA SOA shifted the $\mathrm{O}: \mathrm{C}$ ratio to higher values relative to the paired pre-treatment SOA. Each of these post-treatment experiments were performed the same day as treatment except for the Abies grandis unidentified + MeJA stress experiment (AG-1-Post). The unidentified stress post-treatment experiment resulted in an increase of $\mathrm{O}: \mathrm{C}$ from 0.19 in the pretreatment SOA to 0.29 in the post-treatment SOA. This effect could have been due to the stress treatment or it could have been due to the unidentified stress waning after the trees were transported to the laboratory - the post-treatment $\mathrm{O}: \mathrm{C}$ was still not as high as most pre-treatment SOA.

For all the same-day post-treatment experiments, the increased $\mathrm{O}: \mathrm{C}$ could be due to the oxidation products of the plant hormone, MeJA. The elemental ratios from the SOA generated from the oxidation of the single-component MeJA standard are also shown in Fig. 9b in black. Expected elemental ratios calculated from the optimized linear addition of the baseline spectra and the MeJA standard spectra yielded elemental ratios that were within $10 \%$ of those measured for the paired post-treatment experiment (for same-day treatment/growth experiment only). This suggests that most of the increase in the O:C may have been due to the MeJA and its oxidation products rather than the influence of specific stress compounds in the SOA spectra. However, the pre-treatment Picea pungens experiment where the plants appeared to be in a stressed condition also had higher $\mathrm{O}: \mathrm{C}$ in approximately the same Van Krevelen space as these other post-treatment SOA. This suggests there are compounds other than MeJA and its oxidation products that could also produce SOA in this region of the Van Krevelen plot.

\subsection{Results summary}

The number of experiments and types of tree species examined in this study has provided a rich, but complex, data set. When experiments are grouped into categories by common characteristics, clear patterns emerge in the data. First, we find that the SOA generation methods used in this study were highly reproducible as evidenced by results from the three paired pre-treatment/negative control experiments where all SOA spectra comparisons produced correlations greater than 0.990 . These results put all other comparisons in context and suggest that any correlations less than 0.90 do truly represent a difference between SOA mass spectra.

Most of the pre-treatment SOA generated from emissions of all tree species had very similar UMR SOA spectra with nearly $80 \%$ of all pre-treatment SOA comparisons having an $r^{2}$ greater than 0.90 . This result, when combined with the diversity in pre-treatment monoterpenoid emission profiles from these trees presented in Faiola et al. (2015), suggests that aerosol mass spectra of biogenic SOA formed from ozone-initiated chemistry under baseline conditions all look very similar even with a different mix of monoterpenes used to generate the SOA. These results are consistent with findings presented by Kiendler-Scharr et al. (2009) who found similar AMS characteristics between biogenic SOA generated from the emissions of different types of plant species. In contrast, results from HR data analysis showed a higher degree of variability between pre-treatment biogenic SOA with $\mathrm{O}: \mathrm{C}$ values ranging from 0.30 to 0.47 (excluding the UNID stress experiment).

The presence of stress led to significant differences in the UMR SOA spectra. For example, the SOA spectrum that was least similar to all other SOA spectra was generated from the emissions of Abies grandis after the saplings had apparently been exposed to an unidentified stressor before being transported to the lab. Consequently, these results were not reproducible but did serve as an opportunity to investigate a plant's response to a natural stressor. The presence of substantial, discernible peaks in the UMR spectrum around $\mathrm{m} / \mathrm{z}$ 200 indicated the presence of higher molecular weight emissions that were not identified with the GC system. Large 17carbon compounds have been observed as a plant's response to certain types of herbivores and, when observed previously, resulted in substantially increased SOA yields (Mentel et al., 2013). The AG-1-Pre results may have been due to a similar phenomenon. The amount of SOA produced from these emissions was substantial (>500 $\mu \mathrm{g} \mathrm{m}^{-3}$ ) and had a significantly lower $\mathrm{O}: \mathrm{C}$ than any other SOA reported here or reported elsewhere (Chhabra et al., 2010). Other enhanced $\mathrm{m} / \mathrm{z}$ in the UNID stress spectra were $\mathrm{m} / z 31$ and $\mathrm{m} / z 58$ corresponding to $\mathrm{HR}$ ions $\mathrm{CH}_{3} \mathrm{O}^{+}, \mathrm{C}_{2} \mathrm{H}_{2} \mathrm{O}_{2}^{+}$, and $\mathrm{C}_{3} \mathrm{H}_{6} \mathrm{O}^{+}$.

The other SOA spectra that had the lowest correlation coefficients when compared to pre-treatment SOA were the 2013 post-treatment SOA. We attempted to remove the influence of MeJA, and its oxidation products, on the same-day 
post-treatment SOA spectra. The resulting residual spectra highlighted differences to the SOA spectra that were due to the plants response to the stress treatment. The same $m / z$ that were enhanced in the UNID spectra, $\mathrm{m} / z 31$ and $\mathrm{m} / z 58$ (HR ions $\mathrm{CH}_{3} \mathrm{O}^{+}, \mathrm{C}_{2} \mathrm{H}_{2} \mathrm{O}_{2}^{+}, \mathrm{C}_{3} \mathrm{H}_{6} \mathrm{O}^{+}$) were also enhanced in each of the residual spectra. Other prevalent $m / z$ in the residual spectra were $m / z 29$ (primarily $\mathrm{C}_{2} \mathrm{H}_{5}^{+}$enhancement), $m / z 57\left(\mathrm{C}_{3} \mathrm{H}_{5} \mathrm{O}^{+}\right), m / z 59\left(\mathrm{C}_{2} \mathrm{H}_{3} \mathrm{O}_{2}^{+}\right.$and $\left.\mathrm{C}_{3} \mathrm{H}_{7} \mathrm{O}^{+}\right), m / z$ $71\left(\mathrm{C}_{3} \mathrm{H}_{3} \mathrm{O}_{2}^{+}\right.$and $\mathrm{C}_{4} \mathrm{H}_{7} \mathrm{O}^{+}$), and $m / z 83$ (primarily $\mathrm{C}_{5} \mathrm{H}_{7} \mathrm{O}^{+}$ enhancement). Ozone is the dominant atmospheric oxidant for many of the terpenoid compounds emitted by vegetation (Atkinson and Arey, 2003). Furthermore, no OH scavenger was used to suppress $\mathrm{OH}$ chemistry. Consequently, these AMS results could be representative of what one would expect in ambient conditions. The enhancement of these ions in ambient data sets should be investigated to search for this possible biogenic stress marker in aerosol spectra collected in a natural forest environment.

Additionally, our results demonstrate that plant hormones, such as MeJA, can contribute to SOA formation and produce distinctive SOA mass spectra with peaks at $m / z 131$ and $m / z$ 157. The standard MeJA SOA was substantially more oxidized than other biogenic SOA as was evidenced by its high relative proportion of $\mathrm{m} / \mathrm{z} 44$ to the total organic mass and its high $\mathrm{O}: \mathrm{C}$ ratio of 0.52 . Plant emissions of stress hormones can equal emissions of monoterpenes under stressed conditions, and others have even suggested using ambient measurements of plant hormones to monitor for plant stress at an ecosystem scale (Karl et al., 2008). It is possible that the mass spectral markers associated with either the plants response to the stress treatment or the markers associated with the MeJA plant hormone directly could also be used to monitor for stress at an ecosystem scale.

\section{Conclusions}

The baseline aerosol mass spectra of biogenic SOA produced from real plant emissions were similar across six different plant species when comparing UMR results. However, the presence of stress appeared to change the composition of the SOA to the extent that the UMR aerosol mass spectra looked significantly different. This mass spectral biogenic stress marker could be indicative of an herbivory stress aerosol signature in the natural forest environment when stressed conditions produce stress-induced emissions including, but not limited to, plant hormones such as MeJA.

Previous work has shown that environmental stresses can have significant and widely varying impacts on BVOC emission rates and emission profiles. Stressors may increase, or sometimes decrease, the amount of BVOCs emitted, and often induce emissions of compounds not emitted under baseline conditions. The work presented here builds on those previous efforts and shows that herbivore-induced emissions not only affect the amount of SOA subsequently formed as shown previously (Mentel et al., 2013), but also affect SOA composition. Both of these herbivore effects will likely impact the aerosol radiative properties. Changes to the amount of SOA produced would have direct impacts on light extinction. The radiative impacts of stress-induced changes to SOA composition, our primary focus in this work, are less clear. For example, the involvement of larger hydrocarbon precursors ( $>15$ carbons) would likely decrease SOA hygroscopicity, whereas the involvement of more oxidized precursors (e.g., MeJA) would likely increase SOA hygroscopicity The net impact is difficult to estimate without a more thorough quantitative understanding of herbivore-induced BVOC emission rates. In addition to radiative effects, it is also possible for new particle formation mechanisms to be enhanced by herbivore-induced BVOCs. Recent findings have shown that biogenic emissions play a critical role in particle nucleation (Riccobono et al., 2014), and thus increases in herbivoreinduced emissions could be expected to enhance particle nucleation in forests. These potential effects need further study, though controlled experiments will remain challenging due to the significant variability in plant behavior that have limited efforts to parameterize stress-induced emissions so far.

Future work on this topic should investigate SOA mass spectral fingerprints for other stressors that could induce emissions of non-terpenoid compounds. For example, any stressor that damages plant membranes produces bursts in 6-carbon oxygenated VOC products from the lipoxygenase pathway. This could be investigated in the laboratory using real herbivores or pathogens that would damage plant tissues. Additionally, tissue damage can occur under severe heat stress. Future work should also generate SOA from the plant hormone methyl salicylate, which is emitted at higher rates than MeJA and still could have oxidation products with low enough volatility to contribute to SOA formation. To our knowledge, SOA has not been generated from this major plant hormone that has been measured at significant levels in a forest environment. Other future studies should focus on analyzing ambient AMS data sets collected in forest environments to investigate whether or not the biogenic stress marker that was identified here can be observed in field measurements. This could serve as a monitoring tool to identify ecosystem-level plant stress.

\section{The Supplement related to this article is available online at doi:10.5194/acp-15-3629-2015-supplement.}


Acknowledgements. The authors thank Chuck Cody and the greenhouse staff for taking care of the plants used in this study. Authors also thank Courtney Herring for answering questions about AMS data analysis. This work was supported by the U.S. Department of Energy Early Career Research Program (award no. SC0003899).

Edited by: P. Artaxo

\section{References}

Acevedo, C., Sánchez, E., Young, M. E., and Simpson, R.: Prediction correlation of vapor pressure for methyl jasmonate, J. Food Eng., 59, 431-433, 2003.

Aiken, A. C., DeCarlo, P. F., Kroll, J. H., Worsnop, D. R., Huffman, J. A., Docherty, K. S., Ulbrich, I. M., Mohr, C., Kimmel, J. R., Sueper, D., Sun, Y., Zhang, Q., Trimborn, A., Northway, M., Ziemann, P. J., Canagaratna, M. R., Onasch, T. B., Alfarra, M. R., Prevot, A. S. H., Dommen, J., Duplissy, J., Metzger, A., Baltensperger, U., and Jimenez, J. L.: O/C and OM/OC Ratios of Primary, Secondary, and Ambient Organic Aerosols with HighResolution Time-of-Flight Aerosol Mass Spectrometry, Environ. Sci. Technol., 42, 4478-4485, doi:10.1021/es703009q, 2008.

Arneth, A., Harrison, S. P., Zaehle, S., Tsigaridis, K., Menon, S., Bartlein, P. J., Feichter, J., Korhola, A., Kulmala, M., O'Donnell, D., Schurgers, G., Sorvari, S., and Vesala, T.: Terrestrial biogeochemical feedbacks in the climate system, Nat. Geosci, 3, 525532, doi:10.1038/ngeo905, 2010.

Atkinson, R. and Arey, J.: Gas-phase tropospheric chemistry of biogenic volatile organic compounds: a review, Atmos. Environ., 37, 197-219, doi:10.1016/S1352-2310(03)00391-1, 2003.

Bahreini, R., Keywood, M. D., Ng, N. L., Varutbangkul, V., Gao, S., Flagan, R. C., Seinfeld, J. H., Worsnop, D. R., and Jimenez, J. L.: Measurements of secondary organic aerosol from oxidation of cycloalkenes, terpenes, and m-xylene using an Aerodyne aerosol mass spectrometer, Environ. Sci. Technol., 39, 5674-5688, 2005.

Canagaratna, M. R., Jayne, J. T., Jimenez, J. L., Allan, J. D., Alfarra, M. R., Zhang, Q., Onasch, T. B., Drewnick, F., Coe, H., Middlebrook, A., Delia, A., Williams, L. R., Trimborn, A. M., Northway, M. J., DeCarlo, P. F., Kolb, C. E., Davidovits, P., and Worsnop, D. R.: Chemical and microphysical characterization of ambient aerosols with the aerodyne aerosol mass spectrometer, Mass Spectrom. Rev., 26, 185-222, doi:10.1002/mas.20115, 2007.

Canagaratna, M. R., Jimenez, J. L., Kroll, J. H., Chen, Q., Kessler, S. H., Massoli, P., Hildebrandt Ruiz, L., Fortner, E., Williams, L. R., Wilson, K. R., Surratt, J. D., Donahue, N. M., Jayne, J. T., and Worsnop, D. R.: Elemental ratio measurements of organic compounds using aerosol mass spectrometry: characterization, improved calibration, and implications, Atmos. Chem. Phys., 15, 253-272, doi:10.5194/acp-15-253-2015, 2015.

Carslaw, K. S., Boucher, O., Spracklen, D. V., Mann, G. W., Rae, J. G. L., Woodward, S., and Kulmala, M.: A review of natural aerosol interactions and feedbacks within the Earth system, Atmos. Chem. Phys., 10, 1701-1737, doi:10.5194/acp-10-17012010, 2010.
Cheong, J.-J. and Choi, Y. D.: Methyl jasmonate as a vital substance in plants, Trends Genet., 19, 409-413, doi:10.1016/S01689525(03)00138-0, 2003.

Chhabra, P. S., Flagan, R. C., and Seinfeld, J. H.: Elemental analysis of chamber organic aerosol using an aerodyne high-resolution aerosol mass spectrometer, Atmos. Chem. Phys., 10, 4111-4131, doi:10.5194/acp-10-4111-2010, 2010.

Copolovici, L., Kaennaste, A., Remmel, T., Vislap, V., and Niinemets, U.: Volatile Emissions from Alnus glutionosa Induced by Herbivory are Quantitatively Related to the Extent of Damage, J. Chem. Ecol., 37, 18-28, doi:10.1007/s10886-010-9897-9, 2011.

Davidson, E. A. and Kingerlee, W.: A global inventory of nitric oxide emissions from soils, Nutr. Cycl. Agroecosystems, 48, 37-50, 1997.

De Boer, J. G., Posthumus, M. A., and Dicke, M.: Identification of volatiles that are used in discrimination between plants infested with prey or nonprey herbivores by a predatory mite, J. Chem. Ecol., 30, 2215-2230, 2004.

DeCarlo, P. F., Kimmel, J. R., Trimborn, A., Northway, M. J., Jayne, J. T., Aiken, A. C., Gonin, M., Fuhrer, K., Horvath, T., Docherty, K. S., Worsnop, D. R., and Jimenez, J. L.: Field-Deployable, High-Resolution, Time-of-Flight Aerosol Mass Spectrometer, Anal. Chem., 78, 8281-8289, doi:10.1021/ac061249n, 2006.

Dudareva, N., Negre, F., Nagegowda, D. A., and Orlova, I.: Plant volatiles: recent advances and future perspectives, Crit. Rev. Plant Sci., 25, 417-440, 2006.

Faiola, C. L., Erickson, M. H., Fricaud, V. L., Jobson, B. T., and VanReken, T. M.: Quantification of biogenic volatile organic compounds with a flame ionization detector using the effective carbon number concept, Atmos. Meas. Tech., 5, 1911-1923, doi:10.5194/amt-5-1911-2012, 2012.

Faiola, C. L., VanderSchelden, G. S., Wen, M., Elloy, F. C., Cobos, D. R., Watts, R. J., Jobson, B. T., and VanReken, T. M.: SOA Formation Potential of Emissions from Soil and Leaf Litter, Environ. Sci. Technol., 48, 938-946, 2014.

Faiola, C. L., Jobson, B. T., and VanReken, T. M.: Impacts of simulated herbivory on volatile organic compound emission profiles from coniferous plants, Biogeosciences, 12, 527-547, doi:10.5194/bg-12-527-2015, 2015.

Farmer, E. E. and Ryan, C. A.: Interplant communication: airborne methyl jasmonate induces synthesis of proteinase inhibitors in plant leaves, P. Natl. Acad. Sci. USA, 87, 7713, doi:10.1073/pnas.87.19.7713, 1990.

Hallquist, M., Wenger, J. C., Baltensperger, U., Rudich, Y., Simpson, D., Claeys, M., Dommen, J., Donahue, N. M., George, C., Goldstein, A. H., Hamilton, J. F., Herrmann, H., Hoffmann, T., Iinuma, Y., Jang, M., Jenkin, M. E., Jimenez, J. L., Kiendler-Scharr, A., Maenhaut, W., McFiggans, G., Mentel, Th. F., Monod, A., Prévôt, A. S. H., Seinfeld, J. H., Surratt, J. D., Szmigielski, R., and Wildt, J.: The formation, properties and impact of secondary organic aerosol: current and emerging issues, Atmos. Chem. Phys., 9, 5155-5236, doi:10.5194/acp-9-51552009, 2009.

Hao, L. Q., Romakkaniemi, S., Yli-Pirilä, P., Joutsensaari, J., Kortelainen, A., Kroll, J. H., Miettinen, P., Vaattovaara, P., Tiitta, P., Jaatinen, A., Kajos, M. K., Holopainen, J. K., Heijari, J., Rinne, J., Kulmala, M., Worsnop, D. R., Smith, J. N., and Laaksonen, A.: Mass yields of secondary organic aerosols from the oxida- 
tion of $\alpha$-pinene and real plant emissions, Atmos. Chem. Phys., 11, 1367-1378, doi:10.5194/acp-11-1367-2011, 2011.

Holopainen, J. K.: Multiple functions of inducible plant volatiles, Trends Plant Sci., 9, 529-533, 2004.

Jimenez, J. L., Canagaratna, M. R., Donahue, N. M., Prevot, A. S. H., Zhang, Q., Kroll, J. H., DeCarlo, P. F., Allan, J. D., Coe, H., Ng, N. L., Aiken, A. C., Docherty, K. S., Ulbrich, I. M., Grieshop, A. P., Robinson, A. L., Duplissy, J., Smith, J. D., Wilson, K. R., Lanz, V. A., Hueglin, C., Sun, Y. L., Tian, J., Laaksonen, A., Raatikainen, T., Rautiainen, J., Vaattovaara, P., Ehn, M., Kulmala, M., Tomlinson, J. M., Collins, D. R., Cubison, M. J. E., Dunlea, J., Huffman, J. A., Onasch, T. B., Alfarra, M. R., Williams, P. I., Bower, K., Kondo, Y., Schneider, J., Drewnick, F., Borrmann, S., Weimer, S., Demerjian, K., Salcedo, D., Cottrell, L., Griffin, R., Takami, A., Miyoshi, T., Hatakeyama, S., Shimono, A., Sun, J. Y., Zhang, Y. M., Dzepina, K., Kimmel, J. R., Sueper, D., Jayne, J. T., Herndon, S. C., Trimborn, A. M., Williams, L. R., Wood, E. C., Middlebrook, A. M., Kolb, C. E., Baltensperger, U., and Worsnop, D. R.: Evolution of Organic Aerosols in the Atmosphere, Science, 326, 1525-1529, doi:10.1126/science.1180353, 2009.

Joutsensaari, J., Loivamäki, M., Vuorinen, T., Miettinen, P., Nerg, A.-M., Holopainen, J. K., and Laaksonen, A.: Nanoparticle formation by ozonolysis of inducible plant volatiles, Atmos. Chem. Phys., 5, 1489-1495, doi:10.5194/acp-5-1489-2005, 2005.

Karl, T., Guenther, A., Turnipseed, A., Patton, E. G., and Jardine, K.: Chemical sensing of plant stress at the ecosystem scale, Biogeosciences, 5, 1287-1294, doi:10.5194/bg-5-1287-2008, 2008.

Kesselmeier, J. and Staudt, M.: Biogenic volatile organic compounds (VOC): an overview on emission, physiology and ecology, J. Atmos. Chem., 33, 23-88, 1999.

Kiendler-Scharr, A., Zhang, Q., Hohaus, T., Kleist, E., Mensah, A., Mentel, T. F., Spindler, C., Uerlings, R., Tillmann, R., and Wildt, J.: Aerosol Mass Spectrometric Features of Biogenic SOA: Observations from a plant chamber and in rural atmospheric environments, Env. Sci Technol, 43, 8166-8172, 2009.

Kroll, J. H. and Seinfeld, J. H.: Chemistry of secondary organic aerosol: Formation and evolution of low-volatility organics in the atmosphere, Atmos. Environ., 42, 3593-3624, doi:10.1016/j.atmosenv.2008.01.003, 2008.

Lang-Yona, N., Rudich, Y., Mentel, Th. F., Bohne, A., Buchholz, A., Kiendler-Scharr, A., Kleist, E., Spindler, C., Tillmann, R., and Wildt, J.: The chemical and microphysical properties of secondary organic aerosols from Holm Oak emissions, Atmos. Chem. Phys., 10, 7253-7265, doi:10.5194/acp-10-7253-2010, 2010.

Magnani, F., Mencuccini, M., Borghetti, M., Berbigier, P., Berninger, F., Delzon, S., Grelle, A., Hari, P., Jarvis, P. G., Kolari, P., Kowalski, A. S., Lankreijer, H., Law, B. E., Lindroth, A., Loustau, D., Manca, G., Moncrieff, J. B., Rayment, M., Tedeschi, V., Valentini, R., and Grace, J.: The human footprint in the carbon cycle of temperate and boreal forests, Nature, 447, 849-851, 2007.

Martin, D. M., Gershenzon, J., and Bohlmann, J.: Induction of volatile terpene biosynthesis and diurnal emission by methyl jasmonate in foliage of Norway spruce, Plant Physiol., 132, 1586, doi:10.1104/pp.103.021196, 2003.

Mentel, Th. F., Wildt, J., Kiendler-Scharr, A., Kleist, E., Tillmann, R., Dal Maso, M., Fisseha, R., Hohaus, Th., Spahn, H., Uerlings,
R., Wegener, R., Griffiths, P. T., Dinar, E., Rudich, Y., and Wahner, A.: Photochemical production of aerosols from real plant emissions, Atmos. Chem. Phys., 9, 4387-4406, doi:10.5194/acp9-4387-2009, 2009.

Mentel, Th. F., Kleist, E., Andres, S., Dal Maso, M., Hohaus, T., Kiendler-Scharr, A., Rudich, Y., Springer, M., Tillmann, R., Uerlings, R., Wahner, A., and Wildt, J.: Secondary aerosol formation from stress-induced biogenic emissions and possible climate feedbacks, Atmos. Chem. Phys., 13, 8755-8770, doi:10.5194/acp-13-8755-2013, 2013.

Mwaniki, G. R., Rosenkrance, C., Wallace, H. W., Jobson, B. T., Erickson, M. H., Lamb, B. K., Zalakeviciute, R., and VanReken, T. M.: Factors Contributing to Elevated Concentrations of PM2.5 during Wintertime near Boise, Idaho, Atmos. Poll. Res., 14, 96103, doi:10.5094/APR.2014.012, 2014.

Ng, N. L., Canagaratna, M. R., Zhang, Q., Jimenez, J. L., Tian, J., Ulbrich, I. M., Kroll, J. H., Docherty, K. S., Chhabra, P. S., Bahreini, R., Murphy, S. M., Seinfeld, J. H., Hildebrandt, L., Donahue, N. M., DeCarlo, P. F., Lanz, V. A., Prévôt, A. S. H., Dinar, E., Rudich, Y., and Worsnop, D. R.: Organic aerosol components observed in Northern Hemispheric datasets from Aerosol Mass Spectrometry, Atmos. Chem. Phys., 10, 46254641, doi:10.5194/acp-10-4625-2010, 2010.

Ng, N. L., Canagaratna, M. R., Jimenez, J. L., Chhabra, P. S., Seinfeld, J. H., and Worsnop, D. R.: Changes in organic aerosol composition with aging inferred from aerosol mass spectra, Atmos. Chem. Phys., 11, 6465-6474, doi:10.5194/acp-11-64652011, 2011.

Peñuelas, J. and Staudt, M.: BVOCs and global change, Trends Plant Sci., 15, 133-144, doi:10.1016/j.tplants.2009.12.005, 2010.

Pinto, D., Blande, J., Souza, S., Nerg, A.-M., and Holopainen, J.: Plant Volatile Organic Compounds (VOCs) in Ozone (O3) Polluted Atmospheres: The Ecological Effects, J. Chem. Ecol., 36, 22-34, doi:10.1007/s10886-009-9732-3, 2010.

Riccobono, F., Schobesberger, S., Scott, C. E., Dommen, J., Ortega, I. K., Rondo, L., Almeida, J., Amorim, A., Bianchi, F., Breitenlechner, M., David, A., Downard, A., Dunne, E. M., Duplissy, J., Ehrhart, S., Flagan, R. C., Franchin, A., Hansel, A., Junninen, H., Kajos, M., Keskinen, H., Kupc, A., Kürten, A., Kvashin, A. N., Laaksonen, A., Lehtipalo, K., Makhmutov, V., Mathot, S., Nieminen, T., Onnela, A., Petäjä, T., Praplan, A. P., Santos, F. D., Schallhart, S., Seinfeld, J. H., Sipilä, M., Spracklen, D. V., Stozhkov, Y., Stratmann, F., Tomé, A., Tsagkogeorgas, G., Vaattovaara, P., Viisanen, Y., Vrtala, A., Wagner, P. E., Weingartner, E., Wex, H., Wimmer, D., Carslaw, K. S., Curtius, J., Donahue, N. M., Kirkby, J., Kulmala, M., Worsnop, D. R., and Baltensperger, U.: Oxidation Products of Biogenic Emissions Contribute to Nucleation of Atmospheric Particles, Science, 344, 717-721, 2014.

Richards-Henderson, N. K., Hansel, A. K., Valsaraj, K. T., and Anastasio, C.: Aqueous oxidation of green leaf volatiles by hydroxyl radical as a source of SOA: Kinetics and SOA yields, Atmos. Environ., 95, 105-112, 2014.

Robinson, A. L., Donahue, N. M., Shrivastava, M. K., Weitkamp, E. A., Sage, A. M., Grieshop, A. P., Lane, T. E., Pierce, J. R., and Pandis, S. N.: Rethinking Organic Aerosols: Semivolatile Emissions and Photochemical Aging, Science, 315, 1259-1262, doi:10.1126/science.1133061, 2007. 
Rodriguez-Saona, C., Crafts-Brandner, S. J., Pare, P. W., and Henneberry, T. J.: Exogenous methyl jasmonate induces volatile emissions in cotton plants, J. Chem. Ecol., 27, 679-695, 2001.

Sage, A. M., Weitkamp, E. A., Robinson, A. L., and Donahue, N. M.: Evolving mass spectra of the oxidized component of organic aerosol: results from aerosol mass spectrometer analyses of aged diesel emissions, Atmos. Chem. Phys., 8, 1139-1152, doi:10.5194/acp-8-1139-2008, 2008.

VanReken, T. M., Greenberg, J. P., Harley, P. C., Guenther, A. B., and Smith, J. N.: Direct measurement of particle formation and growth from the oxidation of biogenic emissions, Atmos. Chem. Phys., 6, 4403-4413, doi:10.5194/acp-6-4403-2006, 2006.
Zhang, Q., Jimenez, J. L., Canagaratna, M. R., Allan, J. D., Coe, H., Ulbrich, I., Alfarra, M. R., Takami, A., Middlebrook, A. M., Sun, Y. L., Dzepina, K., Dunlea, E., Docherty, K., DeCarlo, P. F., Salcedo, D., Onasch, T., Jayne, J. T., Miyoshi, T., Shimono, A., Hatakeyama, S., Takegawa, N., Kondo, Y., Schneider, J., Drewnick, F., Borrmann, S., Weimer, S., Demerjian, K., Williams, P., Bower, K., Bahreini, R., Cottrell, L., Griffin, R. J., Rautiainen, J., Sun, J. Y., Zhang, Y. M., and Worsnop, D. R.: Ubiquity and dominance of oxygenated species in organic aerosols in anthropogenically-influenced Northern Hemisphere midlatitudes, Geophys. Res. Lett., available at: http:// www.agu.org/pubs/crossref/2007/2007GL029979.shtml (last access: 22 September 2009), 2007. 